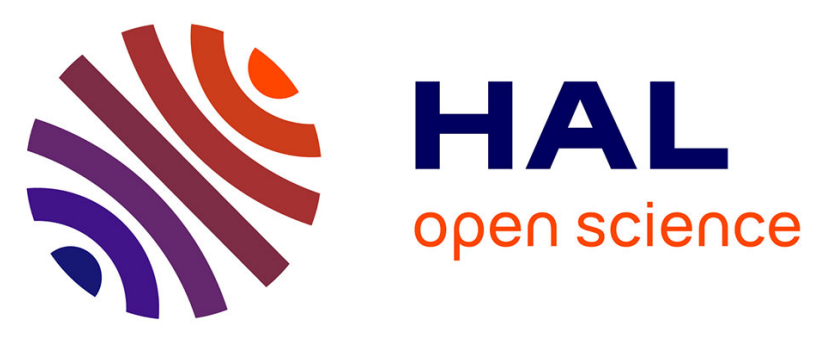

\title{
Development of an LC-ESI(-)-MS/MS method for the simultaneous quantification of 35 isoprostanes and isofurans derived from the major n3- and n6-PUFAs
}

Katharina Maria Rund, Annika I. Ostermann, Laura Kutzner, Jean-Marie Galano, Camille Oger, Claire Vigor, Sabine Wecklein, Nina Seiwert, Thierry

Durand, Nils Helge Schebb

\section{To cite this version:}

Katharina Maria Rund, Annika I. Ostermann, Laura Kutzner, Jean-Marie Galano, Camille Oger, et al.. Development of an LC-ESI(-)-MS/MS method for the simultaneous quantification of 35 isoprostanes and isofurans derived from the major n3- and n6-PUFAs. Analytica Chimica Acta, 2018, 1037, pp.63-74. 10.1016/j.aca.2017.11.002 . hal-02613667

\section{HAL Id: hal-02613667 \\ https://hal.umontpellier.fr/hal-02613667}

Submitted on 3 Jun 2021

HAL is a multi-disciplinary open access archive for the deposit and dissemination of scientific research documents, whether they are published or not. The documents may come from teaching and research institutions in France or abroad, or from public or private research centers.
L'archive ouverte pluridisciplinaire HAL, est destinée au dépôt et à la diffusion de documents scientifiques de niveau recherche, publiés ou non, émanant des établissements d'enseignement et de recherche français ou étrangers, des laboratoires publics ou privés. 


\title{
Development of an LC-ESI(-)-MS/MS method for the simultaneous quantification of 35 isoprostanes and isofurans derived from the major n3- and n6-PUFAs
}

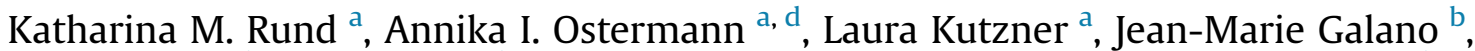 \\ Camille Oger $^{\mathrm{b}}$, Claire Vigor ${ }^{\mathrm{b}}$, Sabine Wecklein ${ }^{\mathrm{c}}$, Nina Seiwert ${ }^{\mathrm{c}}$, Thierry Durand ${ }^{\mathrm{b}}$, \\ Nils Helge Schebb a, d, * \\ a Institute for Food Toxicology, University of Veterinary Medicine Hannover, Bischofsholer Damm 15, 30173 Hannover, Germany \\ ${ }^{\mathrm{b}}$ Institut des Biomolécules Max Mousseron (IBMM), UMR 5247 CNRS, Université de Montpellier, ENSCM, France \\ c Department of Toxicology, University Medical Center Mainz, Obere Zahlbacher Str. 67, 55131 Mainz, Germany \\ d Chair of Food Chemistry, Faculty of Mathematics and Natural Sciences, University of Wuppertal, Gaußstraße 20, 42119 Wuppertal, Germany
}

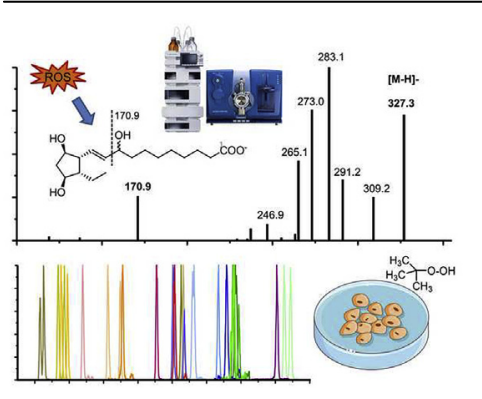

\begin{abstract}
A B S T R A C T
Misregulation of oxidative and antioxidative processes in the organism - oxidative stress - contributes to the pathogenesis of different diseases, e.g. inflammatory or neurodegenerative diseases. Oxidative stress leads to autoxidation of polyunsaturated fatty acids giving rise to prostaglandin-like isoprostanes (IsoP) and isofurans (IsoF). On the one hand they could serve as biomarker of oxidative stress and on the other hand may act as lipid mediators, similarly as the enzymatically formed oxylipins. In the present paper we describe the development of an LC-ESI(-)-MS/MS method allowing the parallel quantification of 27 IsoP and 8 IsoF derived from 6 different PUFA (ALA, ARA, EPA, AdA, n6-DPA, DHA) within 12 min. The chromatographic separation was carried out on an RP-C18 column $(2.1 \times 150 \mathrm{~mm}, 1.8 \mu \mathrm{m})$ yielding narrow peaks with an average width at half maximum of 3.3-4.2 s. Detection was carried out on a triple quadrupole mass spectrometer operating in selected reaction monitoring mode allowing the selective detection of regioisomers. The limit of detection ranged between 0.1 and $1 \mathrm{nM}$ allowing in combination with solid phase extraction the detection of IsoP and IsoF at subnanomolar concentrations in biological samples. The method was validated for human plasma showing high accuracy and precision. Application of the approach on the investigation of oxidative stress in cultured cells indicated a distinct pattern of IsoP and IsoF in response to reactive oxygen species which warrants further investigation.
\end{abstract}

\footnotetext{
* Corresponding author. Chair of Food Chemistry, Faculty of Mathematics and Natural Sciences, University of Wuppertal, Gaußstraße 20, 42119 Wuppertal, Germany.

E-mail address: nils@schebb-web.de (N.H. Schebb).
} 
The described method is not only the most comprehensive approach for the simultaneous quantification of IsoP and IsoF, but it was also integrated in a targeted metabolomics method (Ostermann et al. (2015) Anal Bioanal Chem) allowing the quantification of in total 164 oxylipins formed enzymatically and non-enzymatically within $30.5 \mathrm{~min}$.

\section{Introduction}

Oxidative stress results from misregulation of oxidative and antioxidative mechanisms in the organism and is characterized by increased formation of reactive oxygen and nitrogen species [1-3]. These highly reactive molecules attack biomolecules, thereby e.g. modifying proteins as well as DNA and causing mutations [4]. Oxidative degradation of membrane lipids alters the function of membranes and gives rise to a multitude of reactive and stable products $[5,6]$. Oxidative stress, and thus autoxidation, is associated with the pathophysiology of several diseases including inflammatory, cardiovascular, respiratory and neurodegenerative diseases.

In order to evaluate oxidative stress in health and disease, several biomolecules affected by autoxidation (i.e. proteins, DNA, lipids), their degradation products (e.g. malondialdehyde (MDA)) or endogenous antioxidants (e.g. glutathione (GSH)/glutathione disulfide) are used as common biomarkers [7].

In a multi-laboratory comparison of different oxidative stress markers the measurement of $15-\mathrm{F}_{2 \mathrm{t}}-\mathrm{IsoP}$, an isoprostane derived from arachidonic acid (C20:4 n6, ARA) was found to be promising for the evaluation of the oxidative stress status in vivo [8]. Isoprostanes (IsoP) are prostaglandin-like autoxidation products formed from free PUFA and under physiological conditions dominantly from PUFA esterified in phospholipids [9]. During nonenzymatic, free radical mediated autoxidation, PUFA are initially converted via radical abstraction of a bisallylic hydrogen and subsequent addition of molecular oxygen to hydroperoxy fatty acid radicals (Fig. 1). Depending on the position of the initial radical abstraction, different regioisomeric hydroperoxy radicals are formed. The primary formed hydroperoxy intermediates further undergo secondary reactions leading to a diverse product spectrum. For instance, a sequence of two 5-exo-cyclization steps of the hydroperoxy radicals followed by addition of molecular oxygen and reduction of the side chain hydroperoxide leads to prostaglandin$\mathrm{H}$-like bicyclic endoperoxide intermediates. These are under physiological conditions unstable and react in the presence of reducing agents like GSH to stable F-ring isoprostanes or, when reducing cellular agents are depleted, undergo isomerization to Dor E-ring isomers (Fig. 1) [10]. From ARA, 4 regioisomeric $F_{2}$-IsoPs can be formed each comprising 8 racemic diastereomers leading to a total of 64 possible isomers. However, the regioisomers are formed at different rates with the terminal 5 - and $15-\mathrm{F}_{2}$-IsoP being more abundant compared to the 8- and $12-\mathrm{F}_{2}$-IsoP isomers [11,12]. Also, other PUFA can be converted by an analogous mechanism leading to $F_{1}$-PhytoP from $\alpha$-linolenic acid (C18:3 n3, ALA) and $F_{3}-$ IsoP from eicosapentaenoic acid (C20:5 n3, EPA). Adrenic acid (C22:4 n6, AdA) gives rise to $\mathrm{F}_{2}$-dihomo-IsoP, docosahexaenoic acid (C22:6 n3, DHA) and docosapentaenoic acid (C22:5 n6, n6-DPA) to $\mathrm{F}_{4}$-NeuroP and $\mathrm{F}_{3}-\mathrm{NeuroP}_{\mathrm{n} 6}$, respectively.

The product spectrum during autoxidation is directed by the oxygen content: with increasing oxygen concentration (i.e. partial pressure) the levels of IsoP increase, however, above $21 \%$ no further increase of IsoP occurs while the formation of another class of cyclic PUFA derivatives, the tetrahydrofuran substituted isofurans (IsoF), is significantly elevated in vitro [13]. Based on two proposed formation mechanisms - the cyclic peroxide cleavage pathway and the epoxide hydrolysis pathway -8 regioisomeric isofurans comprising 32 stereoisomers are formed from ARA resulting in a total of 256 possible isomers [13]. Conversion of other PUFA by an analogous mechanism leads to PhytoF [14,15], dihomo-IsoF and NeuroF from ALA, AdA and DHA, respectively.

Moreover, depending on the tissue fatty acid composition a characteristic pattern of the formed isoprostanes results. For example, DHA and AdA are both found in the brain, however AdA is predominantly enriched in myelin which is part of the white matter, whereas DHA is enriched in neurons present in the grey matter [16]. Consequently, $\mathrm{F}_{2}$-dihomo-IsoP are associated with oxidative stress of the white matter, whereas $\mathrm{F}_{4}$-NeuroP are related to oxidative damage of the grey matter in vitro [17].

The analysis of isoprostanes in biological matrices is challenging because of their low concentration and the multitude of possible isomers formed from different PUFA. Several methods using gas chromatography (GC) and liquid chromatography (LC) coupled to mass-spectrometry (MS) as well as immunoassays are described for the analysis [18-38]. Immunoassays like ELISA which only allow the analysis of single isomers are easy to handle and enable high sample throughput. However, due to the multitude of structurally similar isoprostanes, ELISAs are susceptible to cross-reactivity leading to an overestimation compared to LC- and GC-MS methods $[38,39]$. In contrast, chromatographic methods coupled to MS allow the selective and sensitive parallel quantification of multiple isomers derived from a single as well as different PUFA. In addition to sample preparation steps, including extraction and purification, GC-MS requires derivatization of the analytes to volatile derivatives. Since this is more laborious, LC-MS has been predominantly used in the past years [26-34,40,41]. Most LC-MS methods cover only ARA derived $\mathrm{F}_{2}$-IsoP, especially the prominent $15-F_{2 t}$-IsoP isomer $[26-29,32,41]$ or are focused on IsoP derived from a single PUFA $[31,34,40]$. Only few methods have been described enabling the parallel quantification of IsoP derived from different PUFA [30,33,42].

However, keeping the tissue specific PUFA pattern in mind, the simultaneous analysis of a comprehensive set of IsoP and IsoF from all biolocially relevant PUFA is crucial for the evaluation of oxidative stress in vivo independent of the origin of the analyzed biological specimen. Therefore, we developed in the present study a new, sensitive LC-ESI(-)-MS/MS method covering a comprehensive set of IsoP and IsoF from 6 biologically relevant PUFA that was integrated in an established method covering enzymatically formed oxylipins. The mass-spectrometric and chromatographic parameters were optimized and the method performance was thoroughly characterized. Finally, the method was applied on the investigation of the formation of IsoP and IsoF in response to tert-butyl hydroperoxide $(t-\mathrm{BOOH})$ induced oxidative stress in HCT116 cells.

\section{Materials and methods}

\subsection{Chemicals}

The isoprostane standard $15-\mathrm{F}_{2 \mathrm{t}}$-IsoP as well as the deuterated 


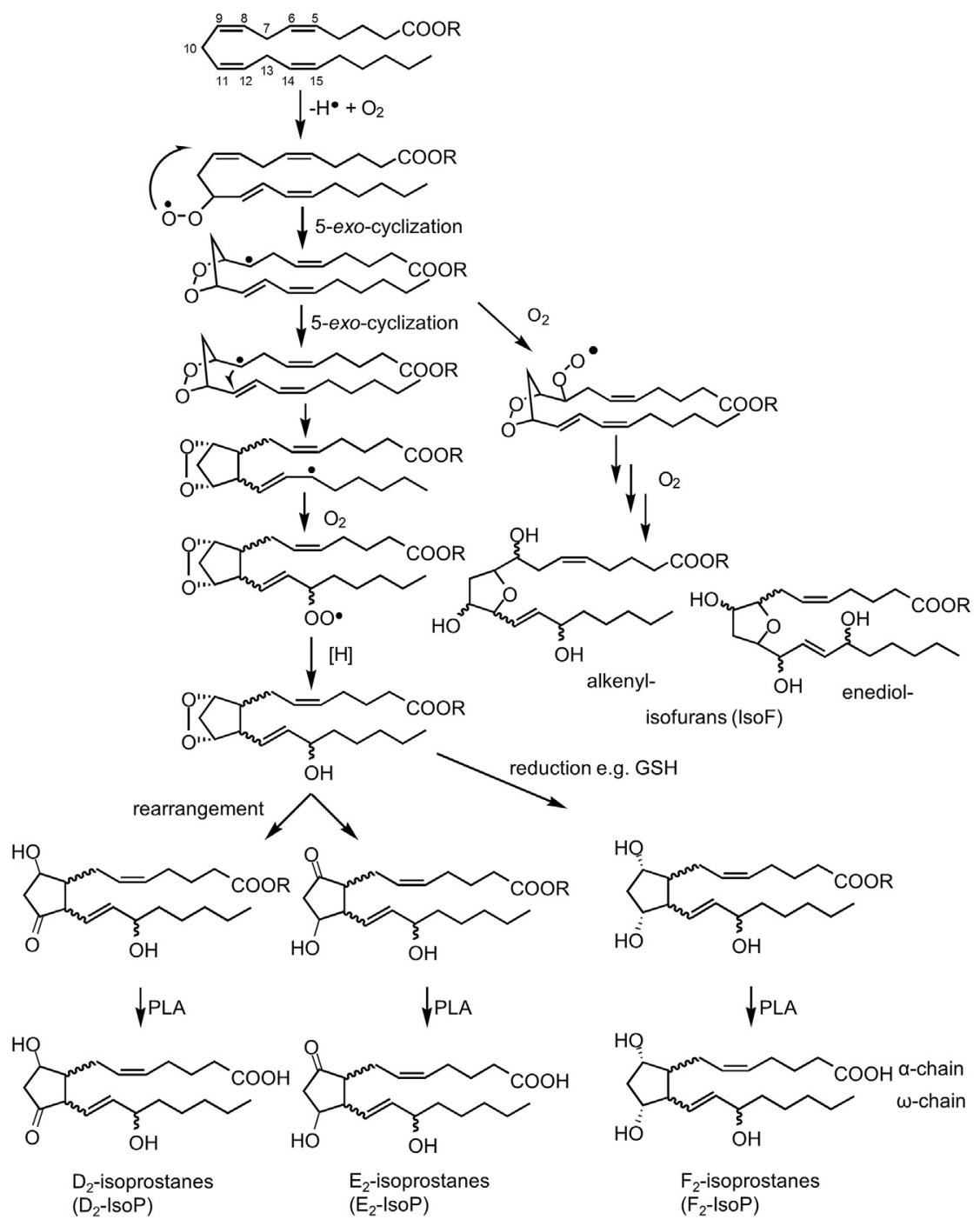

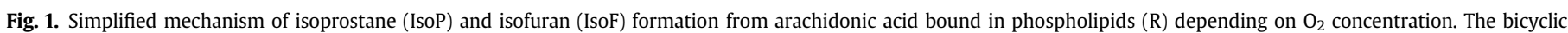

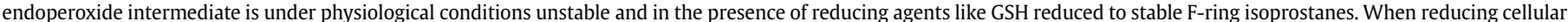
agents are depleted it undergoes isomerization to D- or E-ring isomers. Finally the free oxylipins can be released by phospholipase (PLA).

internal standards (IS) ${ }^{2} \mathrm{H}_{4}-15-\mathrm{F}_{2 \mathrm{t}}$-IsoP $\left({ }^{2} \mathrm{H}_{4}-8-i s o-\mathrm{PGF}_{2 \alpha}\right)$ and ${ }^{2} \mathrm{H}_{11^{-}}$ $5(R, S)-5-\mathrm{F}_{2 \mathrm{t}}-\mathrm{IsoP}\left({ }^{2} \mathrm{H}_{11}-5-\mathrm{iPF}_{2 \alpha}-\mathrm{VI}\right)$ were purchased from Cayman Chemicals (local distributor: Biomol, Hamburg, Germany). All other IsoP and IsoF standards, i.e. ARA derived 5- $\mathrm{F}_{2 \mathrm{t}}$-IsoP, 5-epi-5- $\mathrm{F}_{2 \mathrm{t}}$-IsoP, 2,3-dinor-15- $\mathrm{F}_{2 \mathrm{t}}$-IsoP, 15-epi-2,3-dinor-15- $\mathrm{F}_{2 \mathrm{t}}$-IsoP, EPA derived 5-

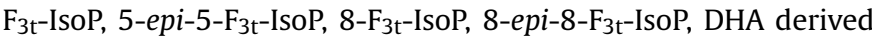
$4(R, S)-4-\mathrm{F}_{4 \mathrm{t}}-$ NeuroP, $10-\mathrm{F}_{4 \mathrm{t}}-$ NeuroP, 10-epi-10-F $4 \mathrm{t}-\mathrm{NeuroP}, 14(R, S)-$ $14-\mathrm{F}_{4 \mathrm{t}}-\mathrm{NeuroP}, 4(R, S)-\mathrm{ST}-\Delta^{5}-8-\mathrm{NeuroF}$, AdA derived $17(R, S)-17-\mathrm{F}_{2 \mathrm{t}^{-}}$ dihomo-IsoP, ent-7(R,S)-7-F 2 -dihomo-IsoP, $17(R, S)-10$-epi-SC- $\Delta^{15}$ 11-dihomo-IsoF, 7(R,S)-ST- $\Delta^{8}$-11-dihomo-IsoF, n6-DPA derived 4-

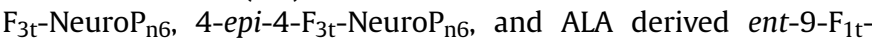
PhytoP, ent-9-epi-9- $\mathrm{F}_{1 \mathrm{t}}-\mathrm{PhytoP}$, ent-16- $\mathrm{F}_{1 \mathrm{t}}-\mathrm{PhytoP}$, ent-16-epi-16$\mathrm{F}_{1 \mathrm{t}}$-PhytoP, 16- $\mathrm{B}_{1}$-PhytoP, 9- $\mathrm{L}_{1}$-PhytoP, ent-16(R,S)-13-epi-ST- $\Delta^{14}$ 9-PhytoF as well as the unlabeled odd-chain IS C19-17-epi-17- F $^{-}{ }^{-}$ PhytoP and $\mathrm{C} 21-15-\mathrm{F}_{2 \mathrm{t}}$-IsoP were synthesized, using our last

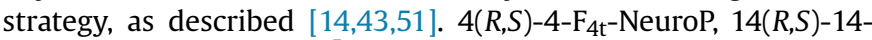
$\mathrm{F}_{4 \mathrm{t}}$-NeuroP, $4(R, S)-\mathrm{ST}-\Delta^{5}$-8-NeuroF, $17(R, S)-17-\mathrm{F}_{2 \mathrm{t}}$-dihomo-IsoP, ent-7(R,S)-7-F $\mathrm{F}_{2 \mathrm{t}}$-dihomo-IsoP, $17(R, S)-10$-epi-SC- $\Delta^{15}-11$-dihomoIsoF, $7(R, S)$-ST- $\Delta^{8}$-11-dihomo-IsoF, ent-16(R,S)-13-epi-ST- $\Delta^{14}$-9PhytoF were only available as epimeric mixtures. LC-MS-grade methanol $(\mathrm{MeOH})$, acetonitrile $(\mathrm{ACN})$ and acetic acid were purchased from Fisher Scientific (Schwerte, Germany). n-Hexane (HPLC Grade) was obtained from Carl Roth (Karlsruhe, Germany). All other chemicals were purchased from Sigma Aldrich (Schnelldorf, Germany). Pooled human EDTA plasma was generated by centrifugation ( $10 \mathrm{~min}, 4^{\circ} \mathrm{C}, 20,000 \times \mathrm{g}$ ) of EDTA blood, followed by mixing plasma from six healthy male and female volunteers aged between 25 and 38 years and immediately stored at $-80{ }^{\circ} \mathrm{C}$ until analysis. All volunteers gave their written informed consent and all procedures were conducted according to the guidelines laid down in the Declaration of Helsinki and approved by the ethic committee at the medical chamber of Lower Saxony (Hannover, Germany).

\subsection{Calibration and quantification of IsoP}

For calibration, stock solutions of the individual analytes (in $\mathrm{MeOH}$ ) were mixed and diluted in glass volumetric flasks (5-100 mL) with $\mathrm{MeOH}$ at 10 concentration levels $(0.1,0.25,0.5,1$, $2,5,10,20,100$ and $500 \mathrm{nM}$ ), each with $20 \mathrm{nM}$ of the four internal standards. Calibration curves were calculated using linear least square regression (weighting: $1 / \mathrm{x}^{2}$ ). Analyte quantification was carried out based on the analyte to corresponding IS (Table 1) area 
Table 1

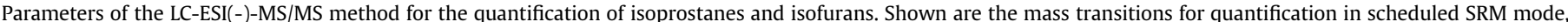

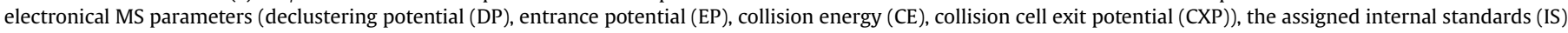

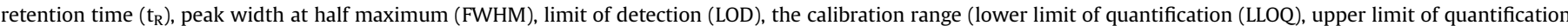
(ULOQ)), correlation coefficient ( $r$ ) and the normalized slope of the calibration curve.

\begin{tabular}{|c|c|c|c|c|c|c|c|c|c|c|c|c|c|c|c|}
\hline \multirow[t]{3}{*}{ Analyte } & \multicolumn{2}{|c|}{$\begin{array}{l}\text { Mass } \\
\text { transition }\end{array}$} & \multicolumn{4}{|c|}{ MS parameters ${ }^{\mathrm{a}}$} & \multirow[t]{3}{*}{ IS } & \multirow{3}{*}{$\begin{array}{l}\mathrm{t}_{\mathrm{R}}^{\mathrm{b}} \\
{[\mathrm{min}]}\end{array}$} & \multirow{3}{*}{$\begin{array}{l}\text { FWHM }^{\mathrm{c}} \\
\overline{[\mathrm{sec}]}\end{array}$} & \multicolumn{2}{|l|}{$\operatorname{LOD}^{\mathrm{d}}$} & \multicolumn{2}{|c|}{$\begin{array}{l}\text { Calibration } \\
\text { range }\end{array}$} & \multirow[t]{3}{*}{$\mathrm{r}^{\mathrm{g}}$} & \multirow[t]{3}{*}{ slope $^{h}$} \\
\hline & \multirow[t]{2}{*}{$\overline{\mathrm{Q} 1}$} & \multirow[t]{2}{*}{ Q3 } & \multirow[t]{2}{*}{$\mathrm{DP}$} & \multirow[t]{2}{*}{$\mathrm{EP}$} & \multirow[t]{2}{*}{$\mathrm{CE}$} & \multirow[t]{2}{*}{$\mathrm{CXP}$} & & & & \multirow[t]{2}{*}{ [nM] } & \multirow{2}{*}{$\begin{array}{l}\text { [pg } \\
\text { on column] }\end{array}$} & \multicolumn{2}{|c|}{$\overline{\text { LLOQ }^{\mathrm{e}} \mathrm{ULOQ}^{\mathrm{f}}}$} & & \\
\hline & & & & & & & & & & & & {$[\mathrm{nM}]$} & & & \\
\hline ent-16(R,S)-13-epi-ST- $\Delta^{14}$-9-PhytoF 1 *) & 343.1 & 200.9 & -80 & -10 & -33 & -8 & C19-17-epi-17- $\mathrm{F}_{1 \mathrm{t}}$-PhytoP & 4.19 & 3.4 & 0.12 & 0.20 & 0.24 & 235 & 0.9993 & 0.91 \\
\hline ent-16(R,S)-13-epi-ST- $\Delta^{14}$-9-PhytoF 2 *) & 343.1 & 200.9 & -80 & -10 & -33 & -8 & C19-17-epi-17- $\mathrm{F}_{1 \mathrm{t}}-\mathrm{PhytoP}$ & 4.30 & 3.4 & 0.13 & 0.23 & 0.26 & 265 & 0.9995 & 1.02 \\
\hline ent-16-epi- $\mathrm{F}_{1 \mathrm{t}}-\mathrm{PhytoP}$ & 327.3 & 225.0 & -70 & -10 & -34 & -8 & C19-17-epi-17- $\mathrm{F}_{1 \mathrm{t}}-\mathrm{PhytoP}$ & 4.72 & 3.3 & 0.25 & 0.41 & 0.50 & 500 & 0.9983 & 0.78 \\
\hline ent-16- $\mathrm{F}_{1 \mathrm{t}}-\mathrm{PhytoP}$ & 327.3 & 225.0 & -70 & -10 & -34 & -8 & C19-17-epi-17-F1t-PhytoP & 4.89 & 3.4 & 0.25 & 0.41 & 0.50 & 500 & 0.9997 & 0.73 \\
\hline ent-9- $\mathrm{F}_{1 \mathrm{t}}-\mathrm{PhytoP}$ & 327.3 & 170.9 & -40 & -10 & -31 & -8 & C19-17-epi-17-F 1 t-PhytoP & 4.81 & 3.3 & 0.10 & 0.16 & 0.25 & 500 & 0.9991 & 1.44 \\
\hline ent-9-epi- $\mathrm{F}_{1 \mathrm{t}}-\mathrm{PhytoP}$ & 327.3 & 170.9 & -40 & -10 & -31 & -8 & C19-17-epi-17-F $1 \mathrm{t}^{-}$-PhytoP & 4.98 & 3.3 & 0.25 & 0.41 & 0.50 & 500 & 0.9990 & 1.12 \\
\hline $15(R, S)-2,3$-dinor-15- $\mathrm{F}_{2 \mathrm{t}}$-IsoP & 325.2 & 237.0 & -40 & -10 & -18 & -8 & C19-17-epi-17-F1t-PhytoP & 5.41 & 3.3 & 0.25 & 0.41 & 0.50 & 500 & 0.9995 & 1.79 \\
\hline $8-\mathrm{F}_{3 \mathrm{t}}$-IsoP & 351.1 & 155.0 & -60 & -10 & -27 & -8 & C19-17-epi-17-F 1 -PhytoP & 6.15 & 3.6 & 0.50 & 0.88 & 1.0 & 500 & 0.9980 & 0.70 \\
\hline 8-epi-8-F $3 \mathrm{t}^{-\mathrm{IsoP}}$ & 351.1 & 155.0 & -60 & -10 & -27 & -8 & C19-17-epi-17-F 1 t-PhytoP & 6.51 & 3.3 & 0.50 & 0.88 & 1.0 & 500 & 0.9992 & 0.60 \\
\hline $5(R, S)-5-F_{3 t}$-IsoP & 351.2 & 114.9 & -50 & -10 & -27 & -8 & C19-17-epi-17- $\mathrm{F}_{1 \mathrm{t}}$-PhytoP & 6.53 & 3.4 & 1.0 & 1.8 & 2.0 & 500 & 0.9962 & 0.07 \\
\hline $15-\mathrm{F}_{2 \mathrm{t}}$-IsoP (8-iso-PGF $\left.2 \alpha\right)$ & 353.1 & 193.1 & -70 & -6 & -33 & -8 & ${ }^{2} \mathrm{H}_{4}-15-\mathrm{F}_{2 \mathrm{t}}$-IsoP & 7.56 & 3.7 & 0.25 & 0.44 & 0.50 & 500 & 0.9989 & 0.98 \\
\hline $10-F_{4 t}-$ NeuroP & 377.2 & 153.0 & -40 & -10 & -25 & -8 & ${ }^{2} \mathrm{H}_{4}-15-\mathrm{F}_{2 \mathrm{t}}$-IsoP & 8.04 & 3.3 & 0.25 & 0.47 & 0.50 & 500 & 0.9989 & 1.81 \\
\hline 10-epi-10-F 4 -NeuroP & 377.2 & 153.0 & -40 & -10 & -25 & -8 & ${ }^{2} \mathrm{H}_{4}-15-\mathrm{F}_{2 \mathrm{t}}$-IsoP & 8.37 & 3.5 & 0.50 & 0.95 & 1.0 & 500 & 0.9990 & 0.88 \\
\hline $5(R, S)-5-\mathrm{F}_{2 \mathrm{t}}$-IsoP & 353.2 & 114.8 & -60 & -10 & -26 & -8 & ${ }^{2} \mathrm{H}_{11}-5(R, S)-5-\mathrm{F}_{2 \mathrm{t}}$-IsoP & 8.07 & 3.5 & 0.25 & 0.44 & 0.50 & 500 & 0.9959 & 0.52 \\
\hline $16-B_{1}$-PhytoP & 307.3 & 235.0 & -60 & -10 & -27 & -8 & ${ }^{2} \mathrm{H}_{11}-5(R, S)-5-\mathrm{F}_{2 \mathrm{t}}$-IsoP & 8.26 & 3.7 & 0.10 & 0.15 & 0.25 & 500 & 0.9994 & 3.00 \\
\hline 9- $\mathrm{L}_{1}$-PhytoP & 307.3 & 185.1 & -60 & -10 & -27 & -8 & ${ }^{2} \mathrm{H}_{11}-5(R, S)-5-\mathrm{F}_{2 \mathrm{t}}$-IsoP & 8.33 & 3.7 & 0.10 & 0.15 & 0.25 & 500 & 0.9986 & 3.07 \\
\hline $14(R, S)-14-\mathrm{F}_{4 \mathrm{t}}-$ NeuroP & 377.2 & 205.1 & -50 & -10 & -27 & -8 & $\mathrm{C} 21-15-\mathrm{F}_{2 \mathrm{t}}$-IsoP & 8.62 & 6.5 & 10 & 19 & 20 & 500 & 0.9998 & 0.09 \\
\hline $4(R, S)-4-\mathrm{F}_{4 \mathrm{t}}-\mathrm{NeuroP}$ & 377.1 & 101.3 & -60 & -10 & -26 & -8 & $\mathrm{C} 21-15-\mathrm{F}_{2 \mathrm{t}}$-IsoP & 9.35 & 3.6 & 0.50 & 0.95 & 1.0 & 500 & 0.9982 & 0.23 \\
\hline $4(R, S)-\mathrm{ST}-\Delta^{5}-8$-NeuroF & 393.3 & 187.2 & -40 & -10 & -29 & -8 & C21-15-F 2 -IsoP & 9.59 & 4.2 & 20 & 39 & 40 & 500 & 0.9941 & 0.02 \\
\hline $17(R, S)-17-\mathrm{F}_{2 \mathrm{t}}$-dihomo-IsoP $\left.1 *\right)$ & 381.3 & 263.2 & -90 & -10 & -31 & -8 & $\mathrm{C} 21-15-\mathrm{F}_{2 \mathrm{t}}$-IsoP & 9.78 & 3.6 & 0.63 & 1.2 & 1.3 & 314 & 0.9967 & 0.31 \\
\hline $17(R, S)-17-\mathrm{F}_{2 \mathrm{t}}$-dihomo-IsoP $\left.2 *\right)$ & 381.3 & 263.2 & -90 & -10 & -31 & -8 & $\mathrm{C} 21-15-\mathrm{F}_{2 \mathrm{t}}$-IsoP & 9.95 & 3.2 & 0.37 & 0.71 & 0.75 & 186 & 0.9980 & 0.19 \\
\hline $7(R, S)-\mathrm{ST}-\Delta^{8}$-11-dihomo-IsoF & 397.3 & 245.1 & -50 & -10 & -31 & -8 & $\mathrm{C} 21-15-\mathrm{F}_{2 \mathrm{t}}$-IsoP & 9.81 & $8.9^{\#)}$ & 1.0 & 2.0 & 2.0 & 500 & 0.9993 & 0.42 \\
\hline ent-7(R,S)-7- $\mathrm{F}_{2 \mathrm{t}}$-dihomo-IsoP & 381.3 & 143.0 & -50 & -10 & -31 & -8 & $\mathrm{C} 21-15-\mathrm{F}_{2 \mathrm{t}}$-IsoP & 9.86 & 5.7 & 0.25 & 0.48 & 0.50 & 500 & 0.9972 & 1.87 \\
\hline $4(R, S)-4-\mathrm{F}_{3 \mathrm{t}}-\mathrm{NeuroP}_{\mathrm{n} 6}$ & 379.2 & 101.0 & -50 & -10 & -29 & -8 & $\mathrm{C} 21-15-\mathrm{F}_{2 \mathrm{t}}$-IsoP & 11.03 & 4.1 & 0.50 & 0.95 & 1.0 & 500 & 0.9971 & 0.59 \\
\hline $17(R, S)-10$-epi-SC- $\Delta^{15}$-11-dihomo-IsoF $\left.1 *\right)$ & 397.1 & 221.0 & -90 & -10 & -31 & -8 & $\mathrm{C} 21-15-\mathrm{F}_{2 \mathrm{t}}$-IsoP & 11.26 & 3.7 & 0.52 & 1.0 & 1.0 & 260 & 0.9992 & 0.41 \\
\hline 17(R,S)-10-epi-SC- $\Delta^{15}$-11-dihomo-IsoF $\left.2 *\right)$ & 397.1 & 221.0 & -90 & -10 & -31 & -8 & $\mathrm{C} 21-15-\mathrm{F}_{2 \mathrm{t}}$-IsoP & 11.44 & 3.7 & 0.48 & 0.96 & 0.96 & 240 & 0.9982 & 0.38 \\
\hline C19-17-epi-17- $\mathrm{F}_{1 \mathrm{t}}-\mathrm{PhytoP}$ & 341.3 & 239.0 & -70 & -10 & -35 & -8 & IS & 6.02 & 3.3 & & & & & & \\
\hline${ }^{2} \mathrm{H}_{4}-15-\mathrm{F}_{2 \mathrm{t}}$-IsoP & 357.2 & 196.8 & -50 & -6 & -33 & -8 & IS & 7.54 & 3.6 & & & & & & \\
\hline${ }^{2} \mathrm{H}_{11}-5(R, S)-5-\mathrm{F}_{2 \mathrm{t}^{-}}$-IsoP & 364.3 & 115.2 & -40 & -10 & -29 & -10 & IS & 7.97 & 4.5 & & & & & & \\
\hline C21-15- $\mathrm{F}_{2 \mathrm{t}}$-IsoP & 367.2 & 193.1 & -60 & -10 & -35 & -8 & IS & 9.18 & 3.8 & & & & & & \\
\hline
\end{tabular}

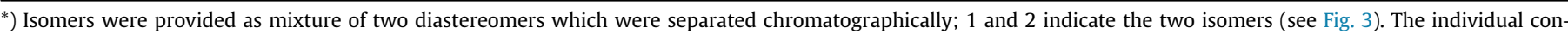
centration of each isomer was calculated based on the ratio in SIM.

a The collision cell exit potential (CXP) was for all analytes $-8 \mathrm{~V}$.

b Relative standard deviation of $t_{R}$ within one batch was $\leq 0.18 \%(<0.01 \mathrm{~min})$.

c Full peak width at half maximum (FWHM) was determined as mean width of standards with the concentrations LLOQ $-100 \mathrm{nM}$, for $14(R, S)-\mathrm{F}_{4 \mathrm{t}}-\mathrm{NeuroP}$ and $4(R, S)-\mathrm{ST}-\Delta^{5}-8$ -

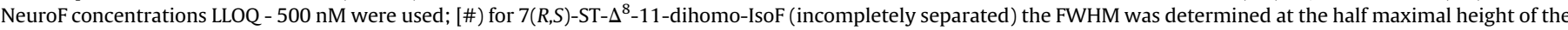
smaller peak (see Fig. $3 \mathrm{~B}(\mathrm{~V})$ )].

d LOD was set to the lowest concentration yielding a signal to noise ratio $>3$.

e LLOQ was set to the lowest calibration standard injected yielding a signal to noise ratio $\geq 5$ and an accuracy in the calibration curve within $\pm 20 \%$.

${ }^{f}$ ULOQ concentration does not represent the end of the dynamic range, but is the highest calibration standard injected.

G Calibration was performed as linear weighted least square regression using $1 / \mathrm{x}^{2}$ weighting.

h Slope of the calibration curve normalized for all analytes to $15-\mathrm{F}_{2 \mathrm{t}}-\mathrm{IsoP} \times 10$.

ratio using the obtained calibration curves.

\subsection{In vitro assay}

HCT116 human colorectal carcinoma cells were grown in $10 \mathrm{~cm}$ dishes $\left(5 \times 10^{6}\right.$ cells/dish) and incubated after $24 \mathrm{~h}$ with $50 \mu \mathrm{M}$ and $200 \mu \mathrm{M}$ of $t-\mathrm{BOOH}$ (Sigma Aldrich, Schnelldorf, Germany) for $30 \mathrm{~min}, 1 \mathrm{~h}$ and $2 \mathrm{~h}$. The cells were then detached using trypsin and harvested by centrifugation $\left(5 \mathrm{~min}, 4^{\circ} \mathrm{C}, 300 \times \mathrm{g}\right.$ ). After a washing step in cold PBS, the cells were centrifuged again $\left(5 \mathrm{~min}, 4^{\circ} \mathrm{C}\right.$, $300 \times g)$ and the supernatant was discarded. The remaining cell pellet was snap-frozen in liquid nitrogen and stored at $-80^{\circ} \mathrm{C}$ until analysis. The cytotoxicity of the used $t-\mathrm{BOOH}$ concentrations was assessed using the MTS assay, which is based on the reduction of the tetrazolium salt MTS (3-(4,5-dimethylthiazol-2-yl)-5-(3carboxymethoxyphenyl)-2-(4-sulfophenyl)-2H-tetrazolium) by viable cells. To this end, HCT116 cells were seeded at a density of $2 \times 10^{4}$ per well and grown overnight. Cells were then incubated with $50 \mu \mathrm{M}$ and $200 \mu \mathrm{M} t-\mathrm{BOOH}$ for $2 \mathrm{~h}$ and the viability was assessed as described [44].

\subsection{Sample extraction}

Human plasma was extracted using anion exchange Bond Elut Certify II SPE cartridges (200 mg, $3 \mathrm{~mL}$, Agilent, Waldbronn, Germany) [45]. In brief, $10 \mu \mathrm{L}$ of IS solution (containing $100 \mathrm{nM}$ of ${ }^{2} \mathrm{H}_{4}$ 15- $\mathrm{F}_{2 \mathrm{t}}$-IsoP, ${ }^{2} \mathrm{H}_{11}-5(R, S)-5-\mathrm{F}_{2 \mathrm{t}}$-IsoP, C19-17-epi-17- $\mathrm{F}_{1 \mathrm{t}}-\mathrm{PhytoP}, \mathrm{C} 21-$ $15-\mathrm{F}_{2 \mathrm{t}}$-IsoP and 13 isotope labeled internal standards used in the targeted metabolomics method [45], Table S2) and $10 \mu \mathrm{L}$ of antioxidant solution $(0.2 \mathrm{mg} / \mathrm{mL}$ BHT and EDTA, $100 \mu \mathrm{M}$ indomethacin, $100 \mu \mathrm{M}$ of the soluble epoxide hydrolase inhibitor trans-4-[4-(3adamantan-1-yl-ureido)-cyclohexyloxy]-benzoic acid (t-AUCB) [46] in $\mathrm{MeOH} /$ water $(50 / 50, v / v)$ ) were added to $500 \mu \mathrm{L}$ freshly thawed human plasma.

The proteins were precipitated by addition of $1400 \mu \mathrm{L}$ ice cold $\mathrm{MeOH}$ and storage at $-80^{\circ} \mathrm{C}$ for at least $30 \mathrm{~min}$. After centrifugation (10 $\mathrm{min}, 4^{\circ} \mathrm{C}, 20,000 \times \mathrm{g}$ ) the supernatant was evaporated under a $\mathrm{N}_{2}$-stream to a volume less than $1 \mathrm{~mL}$ and diluted with $2 \mathrm{~mL}$ of 
0.1 M disodium hydrogen phosphate buffer adjusted to $\mathrm{pH} 5.5$ with acetic acid, thus yielding a $\mathrm{MeOH}$ content of $<17 \%(\mathrm{pH}=6)$.

The SPE cartridge was preconditioned with one column volume of each, ethyl acetate/ $n$-hexane $(75 / 25, v / v)$ containing $1 \%$ acetic acid, $\mathrm{MeOH}$ and $0.1 \mathrm{M}$ disodium hydrogen phosphate adjusted to $\mathrm{pH} 6.0$ with acetic acid in water/MeOH $(95 / 5, v / v)$. After loading onto the preconditioned cartridge, the sample was washed with $3 \mathrm{~mL}$ water and $3 \mathrm{~mL}$ water/MeOH $(50 / 50, v / v)$ and dried with excess pressure of $\mathrm{N}_{2}$ for $1 \mathrm{~min}$. The analytes were eluted with $2 \mathrm{~mL}$ of $75 / 25(v / v)$ ethyl acetate/ $n$-hexane with $1 \%$ acetic acid in tubes containing $6 \mu \mathrm{L}$ of $30 \%$ glycerol in $\mathrm{MeOH}$ as trap solution for the analytes and evaporated until only the glycerol plug remained using a vacuum concentrator ( 1 mbar, $30{ }^{\circ} \mathrm{C}, 45-60 \mathrm{~min}$; Christ, Osterode am Harz, Germany). The residue was resuspended in $50 \mu \mathrm{L} \mathrm{MeOH}$ containing $40 \mathrm{nM}$ of 1-(1-(ethylsulfonyl)piperidin-4yl)-3-(4-(trifluoromethoxy)phenyl)urea as IS2 for the calculation of the extraction efficiency of the IS, centrifuged $\left(10 \mathrm{~min}, 4^{\circ} \mathrm{C}\right.$, $20,000 \times g$ ) and analyzed by LC-MS.

For the analysis of isoprostanes formed in cell incubations, $10 \mu \mathrm{L}$ of antioxidant solution, $50 \mu \mathrm{L}$ water and $300 \mu \mathrm{L} \mathrm{MeOH}$ were added to the cell pellets which contained about $1 \times 10^{7}$ cells. After homogenization in a ball mill (MM 400, Retsch, Haan, Germany) using two $3 \mathrm{~mm}$ stainless steel beads ( $10 \mathrm{~min}, 25 \mathrm{~Hz}$ ), $600 \mu \mathrm{L}$ MTBE was added and the homogenate was vigorously mixed. For separation of the aqueous and the organic layers $300 \mu \mathrm{L} 0.15 \mathrm{M}$ ammonium acetate solution was added. Following mixing and centrifugation (5 min, $4{ }^{\circ} \mathrm{C}, 3500 \times \mathrm{g}$ ), the upper organic layer was transferred to another tube and the aqueous phase was washed with $300 \mu \mathrm{L}$ MTBE. The combined organic layers were evaporated using a vacuum concentrator $\left(1 \mathrm{mbar}, 30^{\circ} \mathrm{C}, 90-120 \mathrm{~min}\right)$. To the residue $10 \mu \mathrm{L}$ IS solution (100 nM, see above), $500 \mu \mathrm{L}$ water/MeOH $(50 / 50, v / v)$ and $300 \mu \mathrm{L} 10 \mathrm{M} \mathrm{NaOH}$ were added and lipids were hydrolyzed for $30 \mathrm{~min}$ at $60{ }^{\circ} \mathrm{C}$. After hydrolysis, the sample was immediately cooled, neutralized using acetic acid (50\%) and mixed with $1900 \mu \mathrm{L}$ $0.1 \mathrm{M}$ disodium hydrogen phosphate buffer $(\mathrm{pH}=6)$. SPE was conducted as described above.

\subsection{Method characterization}

The method was characterized and validated regarding linearity, sensitivity (limit of detection (LOD) and lower limit of quantification (LLOQ)), extraction efficiency, intra- and interday accuracy and precision based on criteria of the guideline on bioanalytical method validation of the European Medicines Agency [47]. Linearity was assessed using standard solutions covering a concentration range from 0.1 to $500 \mathrm{nM}$. The LOD was determined as the concentration yielding a signal to noise ratio $(S / N) \geq 3$. The concentration with a $S /$ $\mathrm{N} \geq 5$ and an accuracy and precision within the calibration curve of $\pm 20 \%$ was defined as LLOQ and set as the lowest concentration of the calibration curve.

The extraction efficiency at three different level of plasma volumes (200, 500 and $1000 \mu \mathrm{L}$ human plasma) was determined as the recovery of the IS spiked to the sample prior extraction calculated using a calibration curve normalized to IS2 which is added in the last step of the analysis.

Intraday accuracy and precision (relative standard deviation, RSD) were evaluated in plasma samples spiked at four concentration levels ( $3 \mathrm{nM}, 10 \mathrm{nM}, 30 \mathrm{nM}, 100 \mathrm{nM}$ in vial) with IsoP and IsoF prior extraction. Four replicates of each level as well as unspiked plasma were analyzed. For interday accuracy and precision the samples were analyzed on 3 days. The accuracy was calculated by comparing the determined concentration with the added concentration. For IsoP isomers detected in unspiked plasma samples this concentration was substracted from the determined concentration following spiking.

\subsection{LC-(ESI-)-MS/MS analysis}

Samples $(5 \mu \mathrm{L})$ were injected into the LC-MS system using a HTS xt-PAL autosampler (CTC Analytics, Switzerland, local distributor: Axel Semrau, Sprockhövel, Germany) equipped with a $100 \mu \mathrm{L}$ syringe and a $20 \mu \mathrm{L}$ sample loop. The sample rack was kept at $4{ }^{\circ} \mathrm{C}$.

Liquid chromatography was performed using a 1290 Infinity LC System (Agilent, Waldbronn, Germany) composed of a binary pump and a column oven. Separation of the analytes was carried out on a Zorbax Eclipse Plus C18 reversed phase column $(2.1 \times 150 \mathrm{~mm}$, particle size $1.8 \mu \mathrm{m}$; Agilent, Waldbronn, Germany) at $40{ }^{\circ} \mathrm{C}$ equipped upstream with an inline filter ( $3 \mu \mathrm{m}, 1290$ infinity II inline filter, Agilent, Waldbronn, Germany) and a SecurityGuard Ultra $\mathrm{C} 18$ cartridge as precolumn $(2.1 \times 2 \mathrm{~mm}$, Phenomenex, Aschaffenburg, Germany). The mobile phase consisted of $0.1 \%$ acetic acid as solvent $\mathrm{A}$ and $800 / 150 / 1(v / v / v)$ ACN/MeOH/acetic acid as solvent $B$. The chromatographic separation was achieved using the following binary gradient with a flow rate of $0.3 \mathrm{~mL} / \mathrm{min}$ : 0-1.0 min isocratic $25 \% \mathrm{~B}, 1.0-1.5$ min linear from $25 \% \mathrm{~B}$ to $30 \% \mathrm{~B}$, 1.5-10.0 min linear from $35 \%$ B to $53 \%$ B, 10.0-19.5 min linear from $53 \%$ B to $68 \%$ B, 19.5-24.5 min linear from $68 \%$ B to $95 \%$ B, 24.5-27.0 min isocratic 95\% B, 27.0-27.10 min linear from 95\% B to $25 \%$ B followed by reconditioning for $3.40 \mathrm{~min}$. During the first $2 \mathrm{~min}$ and the last $6 \mathrm{~min}$ of each run the LC flow was directed to waste using the 2-position-6-port valve integrated in the MS. Detection was carried out on a 6500 QTRAP mass-spectrometer (Sciex, Darmstadt, Germany) following negative electrospray ionization $(\operatorname{ESI}(-))$ with the following source settings: ion-spray voltage $-4500 \mathrm{~V}$, curtain gas $\left(\mathrm{N}_{2}\right)$ : $35 \mathrm{psi}$, nebulizer gas (gas 1 , zero air): 60 psi generated with a zero air generator (UHP-300-ZAS-E, Parker, Kaarst, Germany) and drying gas (gas 2, zero air): $60 \mathrm{psi}$ at a temperature of $475^{\circ} \mathrm{C}$. The offset of the sprayer was $0.250 \mathrm{~cm}$ for the vertical axis and $0.550 \mathrm{~cm}$ for the horizontal axis, the electrode protrusion was approx. $1 \mathrm{~mm}$.

The analytes were detected in scheduled selected reaction monitoring mode (SRM) using nitrogen as collision gas (set to "high", $12 \mathrm{psi}$ ) with a detection window of $\pm 22.5 \mathrm{~s}$ around the expected retention time and a cycle time of $0.4 \mathrm{~s}$. The compound specific parameters were optimized for each analyte and are summarized in Table 1. The LC-MS analysis of isoprostanes and related analytes from other PUFA was combined with an established multimethod for oxylipins $[45,48,49]$. A list of all covered analytes and their mass spectrometric parameters can be found in the supplementary information (SI, Table S1). For data acquisition and instrument control Analyst Software (version 1.6.2, Sciex) and for integration and quantification Multiquant (version 2.1.1, Sciex) was used.

\section{Results and discussion}

For selective and sensitive LC-MS analysis of the isoprostanes and related analytes the mass-spectrometric parameters were optimized for each compound individually and the chromatographic conditions were adjusted in order to yield good and rapid separation of the isobaric isomers.

\subsection{Mass spectrometric detection}

Isoprostanes are autoxidative derivatives of fatty acids containing a carboxylic moiety, thus ionization was carried out in ESI(-) mode leading to the formation of $[\mathrm{M}-\mathrm{H}]^{-}$ions, whose dominating formation was confirmed in MS full scan experiments. For each compound the declustering potential (DP) was optimized in single ion monitoring mode of the $[\mathrm{M}-\mathrm{H}]^{-}$ion to achieve an effective transmission of the ionized analytes from the source to the 
entrance of the vacuum chamber with minimal in-source fragmentation. For selective detection of regioisomers specific fragment ions for selected reaction monitoring (SRM) were chosen from the product ion spectra (SI, Fig. S1) and the collision energy (CE) was optimized. The optimized MS parameters are shown in Table 1. The structure of F-IsoP is characterized by a prostanoid-like F-ring with two hydroxyl groups and one further hydroxyl group in one of the two side chains, either the $\alpha$-chain (carboxy terminus) or the $\omega$-chain (methyl terminus) (Fig. 1). Accordingly, for different regioisomers identical abundant fragments resulting from unspecific loss of $\mathrm{H}_{2} \mathrm{O}$ or $\mathrm{CO}_{2}$ as well as combinations of $\mathrm{CO}_{2}$ and up to 3 fold $\mathrm{H}_{2} \mathrm{O}$ loss were observed (Fig. $2 \mathrm{~A}$ and $\mathrm{B}$ ). Thus, for selective MS detection of different regioisomers the choice of specific fragment ions is crucial. Specific fragments result from backbone fragmentation and can be attributed to $\alpha$-cleavage adjacent to the hydroxyl group in the side chain which is referred to as " $\alpha$-hydroxy- $\beta$-enerearrangement", a common fragmentation for unsaturated hydroxy-fatty acids [50]. For the investigated F-IsoP the observed $\alpha$ fragments comprise the carboxy-terminus with or without subsequent loss of $\mathrm{CO}_{2}$ and/or $\mathrm{H}_{2} \mathrm{O}$. Depending on the side chain where the hydroxyl group is located, the predominantly observed $\alpha$ fragments can be assigned to distinct cleavage sites relative to the hydroxyl group: F-IsoP with the hydroxyl group in the $\alpha$-chain, e.g. ent-9-F 1 -PhytoP (Fig. 2A), showed an $\alpha$-fragmentation which could be attributed to the cleavage on the methyl side of the hydroxyl group leading to a specific fragment containing the carboxyl- and

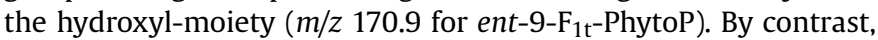
the dominantly observed fragments of F-IsoP with the hydroxyl group in the $\omega$-chain, e.g. ent-16- $\mathrm{F}_{1 \mathrm{t}}$-PhytoP (Fig. 2B) could be assigned to the cleavage on the carboxyl side relative to the hydroxyl group and thus to a fragmentation segment carrying the carboxyl-moiety $\left(\mathrm{m} / \mathrm{z} 269.1\right.$ for ent-16- $\left.\mathrm{F}_{1 \mathrm{t}}-\mathrm{PhytoP}\right)$. Interestingly, the DHA derived $10(R, S)-10-\mathrm{F}_{4 \mathrm{t}}-\mathrm{NeuroP}$ with the hydroxyl group in the $\alpha$-chain and the $14(R, S)-14-\mathrm{F}_{4 \mathrm{t}}-\mathrm{NeuroP}$ with hydroxyl group in the $\omega$-chain are exceptions, showing a reverse fragmentation behavior compared to the observed pattern for the other F-IsoP described above, i.e. forming predominantly charged fragments which can be assigned to the reverse $\alpha$-cleavage site relative to the hydroxyl group (SI, Fig. S1 D(ii) + (iii)). The selected fragment ions are consistent with the transitions used in other SRM methods for almost all F-IsoP with exception of $16(R, S)-16-\mathrm{F}_{1 \mathrm{t}}$-PhytoP [31], $8(R, S)-8-\mathrm{F}_{3 \mathrm{t}}$-IsoP $[32,33]$ and $17(R, S)-17-\mathrm{F}_{2 \mathrm{t}}$-dihomo-IsoP [30,33,51]. For those analytes different transitions compared to existing methods were selected which, however, could be ascribed to specific $\alpha$-cleavages of the backbone of the molecule.

The investigated cyclopentenone PhytoP with B- (Fig. 2C) and Lring structure (SI, Fig. S1 A(iv)) only gave rise to few abundant fragment ions. Based on this fragmentation pattern no suggestion for the site of fragmentation could be made. For structural elucidation of the formed fragments, further studies, e.g. using isotopically labeled standards are necessary. Nevertheless, the selected transitions were specific for these PhytoP and have been reported previously for their quantification [31,34].

The isofurans are structurally characterized by a furan-like 5membered oxygen containing ring carrying a hydroxyl group and additionally two hydroxyl groups in the side chains located either in the same side chain as it is the case for enediol furans or in different side chains like in alkenyl furans (Fig. 1). For each of the investigated IsoF the fragmentation behavior is distinct: Compared to $\mathrm{F}$-IsoP unspecific loss of $\mathrm{H}_{2} \mathrm{O}$ and $\mathrm{CO}_{2}$ is less pronounced and specific fragments resulting from backbone cleavage might be attributed either to fragmentation next to the furan ring (Fig. 2D) or adjacent to one of the side chain hydroxyl groups (as e.g. in $7(R, S)$ ST- $\Delta^{8}$-11-dihomo-IsoF, SI, Fig. S1 E(iii)). However, $4(R, S)-S T-\Delta^{5}-8$ NeuroF and $17(R, S)-10$-epi-SC- $\Delta^{8}$-11-dihomo-IsoF show a different fragmentation pattern (SI, Fig. S1 D(iv), E(iv)) and suggestions for the structure of the fragments and fragmentation sites cannot be made based on the data. For $17(R, S)-10$-epi-SC- $\Delta^{8}$-11-dihomo-IsoF
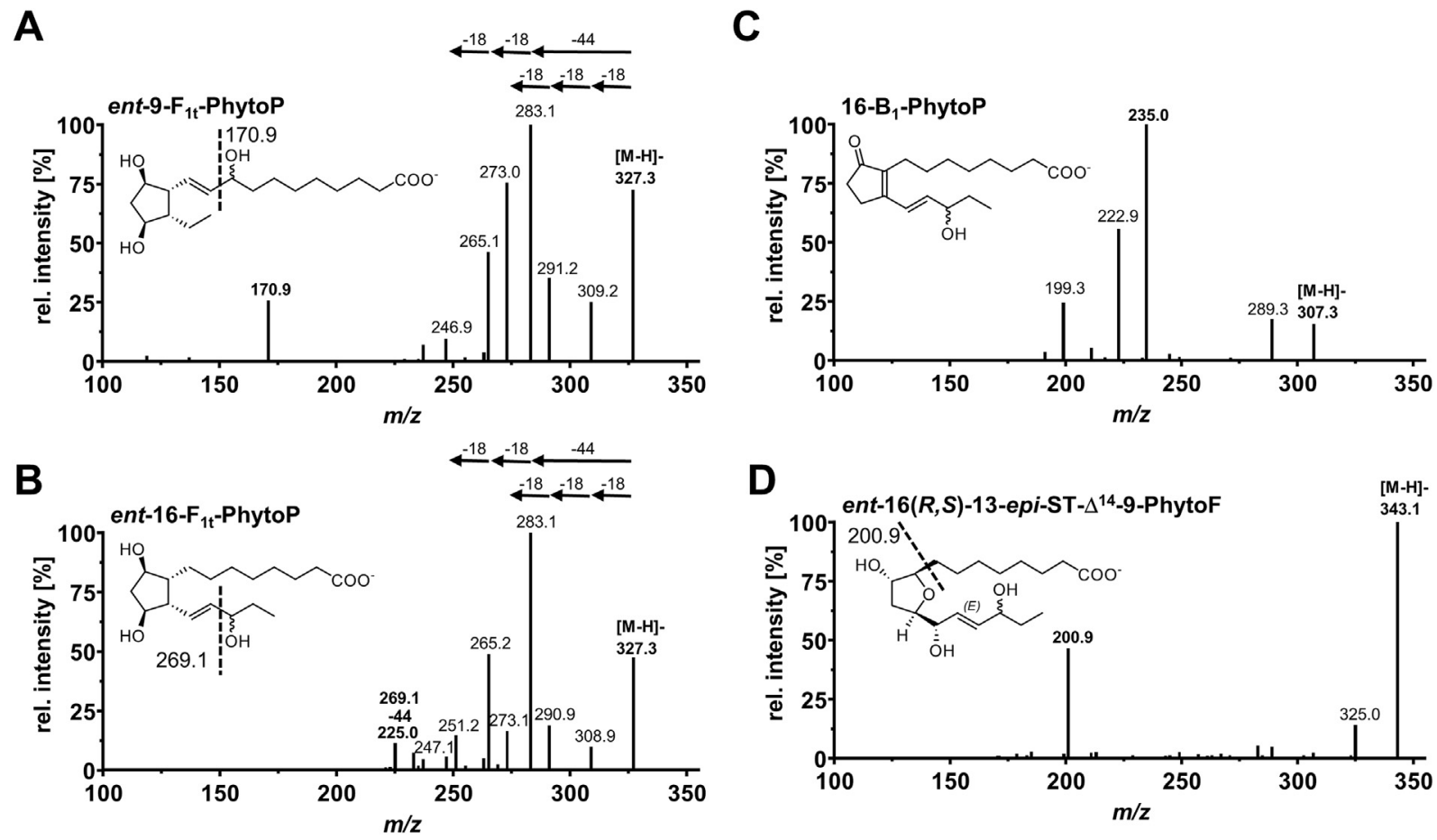

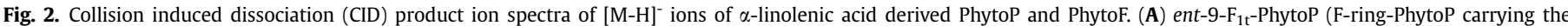

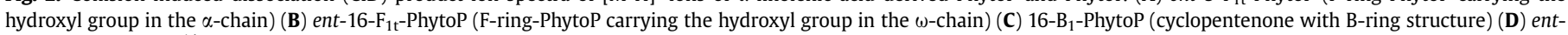
16-(R,S)-13-epi-ST- $\Delta^{14}-9$-PhytoF (enediol-furan). 


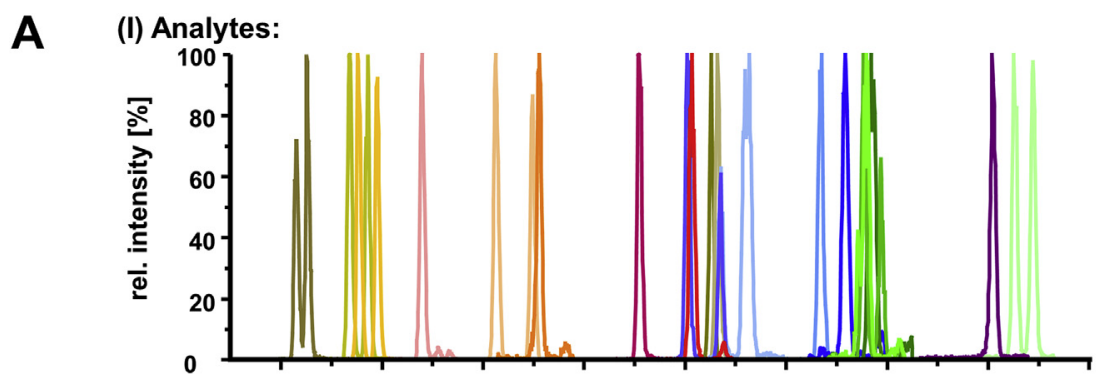

(II) Internal Standards (20 nM):
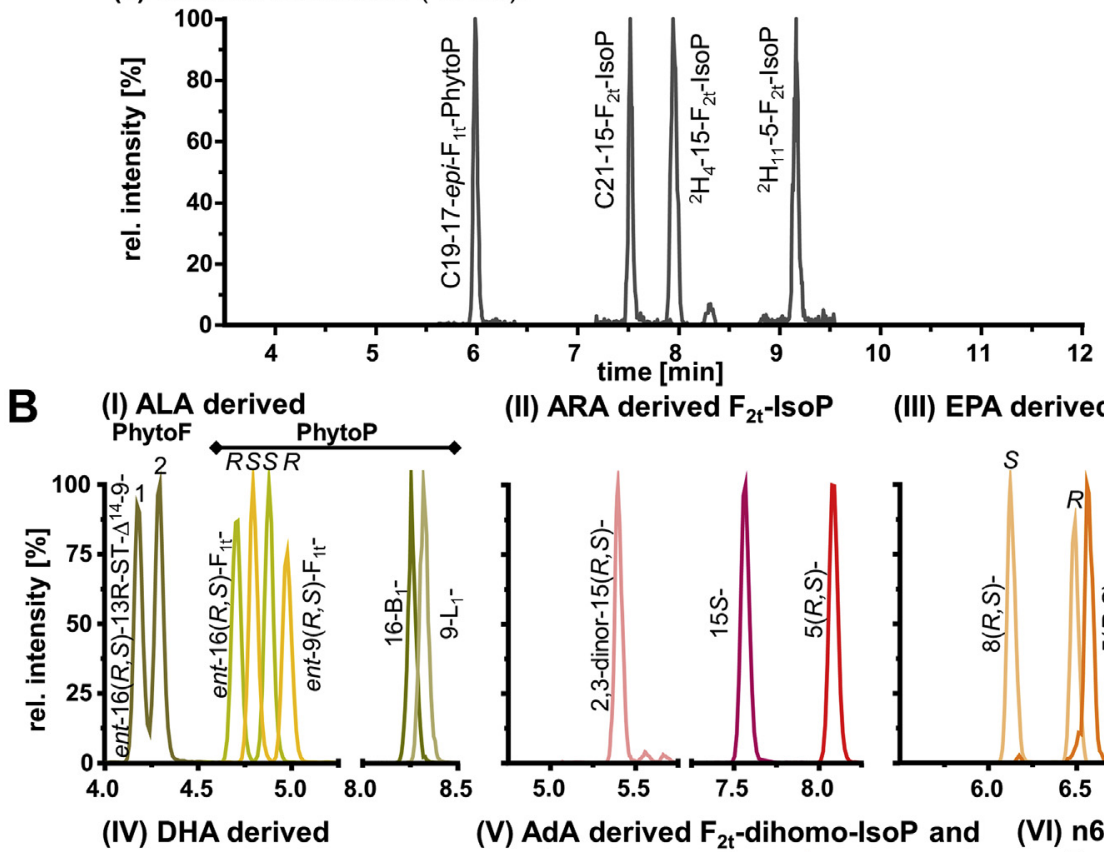

(II) ARA derived $F_{2 t}$-IsoP

(III) EPA derived $F_{3 t^{-}}$-IsoP

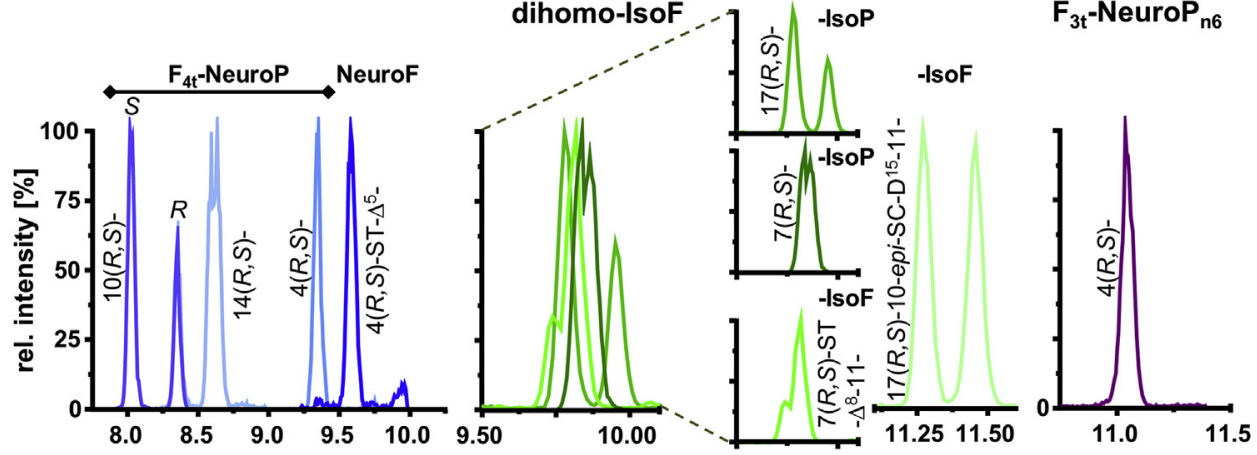

Fig. 3. A: Chromatographic separation of (I) 27 isoprostanes and 8 isofuranes derived from 6 different PUFA. Shown are the SRM signals used for quantification following injection

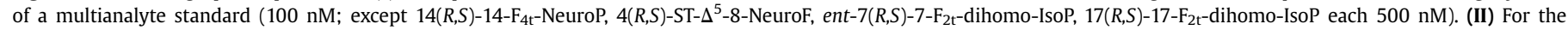
quantification 4 internal standards ( $20 \mathrm{nM}$ ) are used: 2 deuterated IS and 2 odd-chain IS.

B: Chromatographic separation efficiency of isoprostanoids covered by the method grouped by their precursor PUFA. Shown are the SRM signals used for quantification of

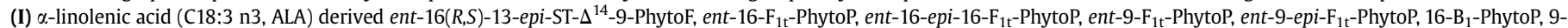
$\mathrm{L}_{1}$-PhytoP.

(II) arachidonic acid (C20:4 n6, ARA) derived 15(R,S)-2,3-dinor-15- $\mathrm{F}_{2 \mathrm{t}}$-IsoP, 15- $\mathrm{F}_{2 \mathrm{t}}-\mathrm{IsoP}$ (= 8-iso- $\mathrm{PGF}_{2 \alpha}$ ), 5(R,S)-5- $\mathrm{F}_{2 \mathrm{t}}$-IsoP.

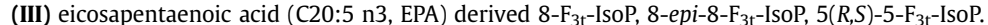

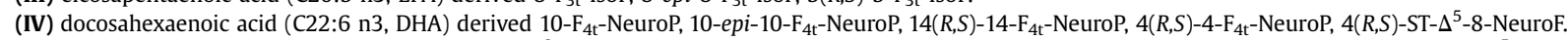

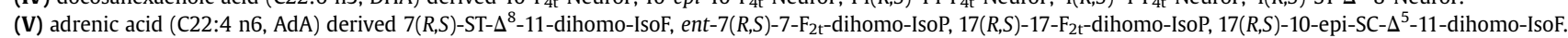

(VI) docosapentaenoic acid (C22:5 n6, n6-DPA) derived 4(R,S)-4- $\mathrm{F}_{3 \mathrm{t}}-\mathrm{NeuroP} \mathrm{P}_{\mathrm{n} 6}$.

the transition reported previously corresponding to the fragment with the highest abundance was selected [51]. Regarding $4(R, S)$-ST$\Delta^{5}$-8-NeuroF the fragment used in previous methods $(\mathrm{m} / \mathrm{z} 123)$ [52] showed poor intensity, thus the fragment $(m / z 187)$ with the highest abundance was selected (SI, Fig. S1 D(iv)).

\subsection{Chromatographic separation}

The chromatographic separation was optimized in order to obtain an efficient separation of the isobaric isomers in a reasonable time. The method covers 25 F-ring IsoP comprising 12 diastereomeric (epimeric) pairs and one single stereoisomer derived 
from ALA, ARA, EPA, n6-DPA, DHA and AdA, one B- and one L-ring PhytoP and 4 epimeric pairs of IsoF derived from ALA, DHA and AdA. Using a C18 column with sub $2 \mu \mathrm{m}$ particles and an optimized gradient of acidified water and $\mathrm{ACN}$ as well as $\mathrm{MeOH}$, separation of the analytes could be achieved within $12 \mathrm{~min}$ (Fig. 3A). The ALA derived PhytoF and $\mathrm{F}_{1 \mathrm{t}}$-PhytoP elute first, followed by the polar $\beta$ oxidation metabolites $15(R, S)-2,3-$ dinor-15- $\mathrm{F}_{2 \mathrm{t}}$-IsoP from ARA and the IsoP from EPA and ARA. B- and L-ring PhytoP and DHA derived $\mathrm{F}_{4 \mathrm{t}}$-NeuroP and NeuroF elute in the middle part of the chromatogram followed by AdA derived $\mathrm{F}_{2 \mathrm{t}}$-dihomo-IsoP and dihomo-IsoF as

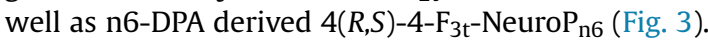

The initial gradient conditions were adjusted in order to achieve separation from the void volume ( $1.5 \mathrm{~min})$, i.e. sufficient retention of the early eluting analytes, which is characterized by a retention factor $\mathrm{k}$ of at least 2. The first analytes (PhytoF) elute at 4.19 and $4.30 \mathrm{~min}$ (after more than two void volumes), which corresponds to a retention factor of $\mathrm{k} \geq 1.8$, showing a sufficient separation from the unretained void volume. The slope of the gradient was optimized in order to yield a high separation efficiency of most epimeric pairs.

A short isocratic step ( $1 \mathrm{~min}$ ) with $25 \%$ organic at the beginning of the gradient was included to focus the analytes at the front end of the column. This led to narrow peaks over the whole separation time (exemplary shown in SI, Fig. S2) characterized by a full width at half maximum (FWHM) of about 3.3-4.2 s for almost all analytes (Table 1). Some epimeric pairs, e.g. $14(R, S)-14-\mathrm{F}_{4 \mathrm{t}}-\mathrm{NeuroP}$ and ent7(R,S)-7-F2t-dihomo-IsoP (Table 1, Fig. 3B), showed a broader FWHM due to incomplete separation of the epimers.

The chromatographic separation showed a high stability regarding retention time with an interbatch $\mathrm{RSD}$ of $\leq 0.25 \%$, i.e. $<$ $0.02 \min (\mathrm{n}=360)$ or $<0.01$ min within one batch $(\mathrm{n}=50)$.

The gradient allows an efficient separation of 7 critical epimeric pairs of IsoP and IsoF characterized by a resolution of $\mathrm{R}>1.5$. With exception of the ent-16(R,S)-13-epi-ST- $\Delta^{14}-9$-PhytoF, which is the first eluting epimeric pair showing a resolution of $\mathrm{R}=1.4$, the resolution of the other separated epimers is $R \geq 1$.7. However, 3

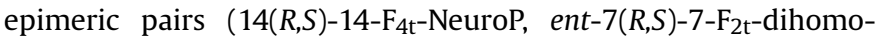
IsoP and $7(R, S)$-ST- $\Delta^{8}$-11-dihomo-IsoF) show an incomplete separation and 6 epimeric pairs coelute (Fig. $3 \mathrm{~B}$ ). The use of a shallower gradient with an increase of $0.5 \% \mathrm{~B} / \mathrm{min}$ instead of $2.7 \% \mathrm{~B} / \mathrm{min}$ or isocratic separation (data not shown) only slightly improved the separation of the incompletely separated and coeluting stereoisomers while further prolonging the analysis time. Thus, only the use of a different column or mobile phase thereby changing the selectivity of the chromatographic system could solve this

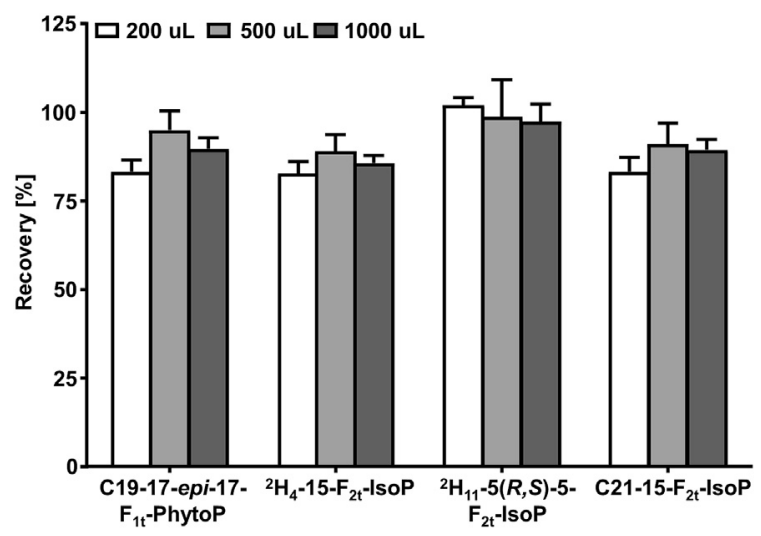

Fig. 4. Recovery of internal standards added to $200 \mu \mathrm{L}, 500 \mu \mathrm{L}$ and $1000 \mu \mathrm{L}$ human plasma at the beginning of sample preparation followed by protein precipitation with $\mathrm{MeOH}$ and solid phase extraction. Shown are mean $\pm \operatorname{SD}(n=4)$. separation problem. However, we regarded these parameters as fixed during method development because the analytical procedure should be integrated in an existing method, already established in our lab for the analysis of enzymatically formed oxylipins $[45,48,49]$. This combination enables to determine 129 oxylipins in addition to the covered IsoP and IsoF, thus allowing the detection of a total of 164 oxylipins formed enzymatically and via autoxidation together with 17 IS within 30.5 min. The mass-spectrometric and chromatographic performance parameters for all analytes are summarized in the SI, Table S1.

\subsection{Method performance}

Quantification of the analytes was carried out based on the analyte to corresponding IS area ratio using the calibration curves. For the IsoP and IsoF two deuterated IsoP $\left({ }^{2} \mathrm{H}_{11}-5(R, S)-5-\mathrm{F}_{2 \mathrm{t}}\right.$-IsoP and ${ }^{2} \mathrm{H}_{4}-15-\mathrm{F}_{2 t}$-IsoP) and two odd-chain unlabeled IsoP (C19-17epi-17- $\mathrm{F}_{1 \mathrm{t}}-\mathrm{PhytoP}$ and $\mathrm{C} 21-15-\mathrm{F}_{2 \mathrm{t}}$-IsoP) that are eluted over the analytical time (Fig. $3 \mathrm{~A}$ ) were used as IS. For $5(R, S)-5-\mathrm{F}_{2 \mathrm{t}}$-IsoP and $15-\mathrm{F}_{2 \mathrm{t}}$-IsoP their respective isotopologs were used as IS. For the other analytes the assignment of the IS was based on retention time (Table 1).

Characterization of the method performance was oriented on the guideline on bioanalytical method validation of the European Medicines Agency [47]. The sensitivity of the method was assessed by determining the LOD and the LLOQ based on the signal to noise ratio (Table 1). The concentration leading to an $\mathrm{S} / \mathrm{N} \geq 3$ was defined as LOD (exemplary shown for 2,3-dinor-15-F2t-IsoP, Fig. S3). Almost all analytes showed a comparable LOD ranging from 0.15 to $2 \mathrm{pg}$ on column. However $14(R, S)-14-\mathrm{F}_{4 \mathrm{t}}-\mathrm{NeuroP}$ and $4(R, S)-\mathrm{ST}-\Delta^{5}-8$ NeuroF showed a considerably higher LOD with $19 \mathrm{pg}$ and $39 \mathrm{pg}$ on column, respectively. Since the same differences in the signal intensity were observed in SIM mode (data not shown), these higher LOD could either be explained by different ionization behavior of the compounds or by impure standard stock solutions of the two compounds. Similar to the LOD, the LLOQ (i.e. the concentration with a $S / N \geq 5$ and an accuracy within $80-120 \%$ of the calibration curve) ranged from 0.25 to $2 \mathrm{nM}$ for almost all IsoP and IsoF except $14(R, S)-14-\mathrm{F}_{4 \mathrm{t}}$-NeuroP and $4(R, S)-\mathrm{ST}-\Delta^{5}-8-$ NeuroF. The sensitivity was also reflected by the slope of the calibration curves. Comparing the slopes of all covered IsoP and IsoF normalized to the same IS revealed that $14(R, S)-14-\mathrm{F}_{4 \mathrm{t}}-\mathrm{NeuroP}$ and $4(R, S)-\mathrm{ST}-\Delta^{5}-8$ NeuroF showed a remarkably lower slope compared to the other analytes (factor 10 and 50 lower, respectively, compared to the mean of normalized slopes) which is consistent with the observed higher LLOQ and LOD (Table 1). Interestingly this higher LLOQ for $14(R, S)-14-\mathrm{F}_{4 \mathrm{t}}-$ NeuroP was also observed previously [33]. Remarkably, $5(R, S)-5-\mathrm{F}_{3 \mathrm{t}}$-IsoP with an LLOQ of $2 \mathrm{nM}$, showed a comparatively low slope. Compared to other IsoP, a slightly higher LLOQ for $5(R, S)-5-\mathrm{F}_{3 \mathrm{t}}$-IsoP was also reported previously [33].

The obtained LOD and LLOQ are in a similar range as reported previously for other oxylipins [45] and in comparison with previous reports for isoprostanes the obtained sensitivity was comparable or slightly better $[30,33]$. Noteworthy, two methods which were focused only on $\mathrm{F}_{2 \mathrm{t}}$-IsoP [41] and PhytoP and PhytoF [34] reported LLOQs one to two orders of magnitude lower despite using a comparable triple quadrupole mass spectrometer. This may be in part explained by the high injection volume of $50 \mu \mathrm{L}$ as well as the use of a micro-HPLC instrumentation [34,41]. In our method, using a higher injection volume led to peak splitting and inacceptable peak shape (SI, Fig. S4). This is caused by the high elution power of the methanol which is used to reconstitute the samples after SPE. Using a more polar solvent leads to an insufficient solution of less polar hydroxy- and epoxy fatty acids which are also covered by our method and thus the amount of sample injected cannot be further 
Table 2

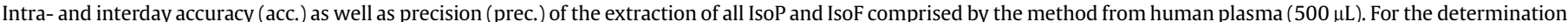

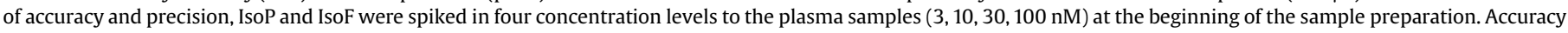

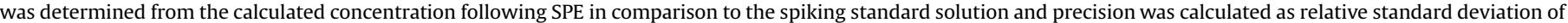

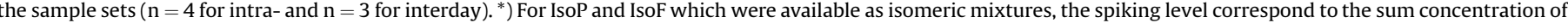
both isomers in the mixture and individual spiking level were calculated based on the isomeric ratio of the substances.

\begin{tabular}{|c|c|c|c|c|c|c|c|c|c|c|c|c|c|}
\hline & \multirow[t]{2}{*}{ Analyte } & \multirow{2}{*}{$\begin{array}{l}\text { conc } \\
{[\mathrm{nM}]}\end{array}$} & \multicolumn{2}{|c|}{ INTRADAY } & \multicolumn{2}{|c|}{ INTERDAY } & \multirow{2}{*}{\multicolumn{2}{|c|}{ Analyte }} & \multirow{2}{*}{$\begin{array}{l}\text { conc } \\
{[\mathrm{nM}]}\end{array}$} & \multicolumn{2}{|c|}{ INTRADAY } & \multicolumn{2}{|c|}{ INTERDAY } \\
\hline & & & acc. $[\%$ & prec.[\%] & acc. [\%] & prec.[\%] & & & & acc.[\%] & prec.[\%] & acc.[\%] & prec.[\%] \\
\hline \multirow[t]{12}{*}{ ARA } & $5(R, S)-5-\mathrm{F}_{2 \mathrm{t}}$-IsoP & 3 & 91 & 4 & 91 & 4 & ALA & ent-9- $\mathrm{F}_{1 \mathrm{t}}-\mathrm{PhytoP}$ & 3 & 103 & 6 & 111 & 4 \\
\hline & & 10 & 84 & 6 & 81 & 3 & & & 10 & 96 & 4 & 98 & 6 \\
\hline & & 30 & 82 & 3 & 78 & 4 & & & 30 & 96 & 3 & 96 & 2 \\
\hline & & 100 & 87 & 8 & 83 & 3 & & & 100 & 99 & 7 & 93 & 1 \\
\hline & $15-\mathrm{F}_{2 \mathrm{t}}$-IsoP (8-iso-PGF $\left.2 \mathrm{a}\right)$ & 3 & 102 & 4 & 108 & 7 & & ent-9-epi-9- $\mathrm{F}_{1 \mathrm{t}}-\mathrm{PhytoP}$ & 3 & 98 & 8 & 109 & 2 \\
\hline & & 10 & 94 & 1 & 94 & 3 & & & 10 & 93 & 2 & 85 & 7 \\
\hline & & 30 & 101 & 6 & 93 & 2 & & & 30 & 93 & 4 & 91 & 4 \\
\hline & & 100 & 97 & 7 & 95 & 0 & & & 100 & 94 & 3 & 87 & 2 \\
\hline & $15(R, S)$-2,3-dinor-15- $\mathrm{F}_{2 \mathrm{t}}$-IsoP & 3 & 88 & 4 & 101 & 7 & & ent-16-epi-16- $\mathrm{F}_{1 \mathrm{t}}-\mathrm{PhytoP}$ & 3 & 112 & 6 & 115 & 9 \\
\hline & & 10 & 89 & 7 & 93 & 2 & & & 10 & 99 & 2 & 100 & 4 \\
\hline & & 30 & 87 & 7 & 80 & 2 & & & 30 & 98 & 3 & 102 & 2 \\
\hline & & 100 & 96 & 7 & 90 & 3 & & & 100 & 100 & 6 & 96 & 5 \\
\hline \multirow[t]{24}{*}{ AdA } & ent-7(R,S)-7- $\mathrm{F}_{2 \mathrm{t}}$-dihomo-IsoP & 3 & 95 & 12 & 105 & 3 & & ent-16- $\mathrm{F}_{1 \mathrm{t}}-\mathrm{PhytoP}$ & 3 & 121 & 4 & 125 & 2 \\
\hline & & 10 & 80 & 7 & 103 & 4 & & & 10 & 99 & 2 & 99 & 4 \\
\hline & & 30 & 92 & 9 & 91 & 6 & & & 30 & 96 & 4 & 101 & 3 \\
\hline & & 100 & 96 & 13 & 90 & 8 & & & 100 & 100 & 6 & 96 & 8 \\
\hline & $17(R, S)-17-\mathrm{F}_{2 \mathrm{t}}$-dihomo-IsoP $\left.1 *\right)$ & 2 & 100 & 10 & 119 & 19 & & 9-- $\mathrm{L}_{1}$-PhytoP & 3 & 99 & 13 & 93 & 1 \\
\hline & & 6 & 100 & 7 & 116 & 2 & & & 10 & 98 & 10 & 91 & 3 \\
\hline & & 19 & 98 & 4 & 100 & 6 & & & 30 & 103 & 18 & 124 & 1 \\
\hline & & 63 & 102 & 12 & 94 & 6 & & & 100 & 95 & 6 & 94 & 5 \\
\hline & $17(R, S)-17-\mathrm{F}_{2 \mathrm{t}}$-dihomo-IsoP $\left.2 *\right)$ & 1 & 106 & 14 & 65 & 15 & & 16-B - $_{1}$-PhytoP & 3 & 101 & 13 & 127 & 8 \\
\hline & & 4 & 77 & 5 & 97 & 21 & & & 10 & 102 & 10 & 100 & 3 \\
\hline & & 11 & 85 & 15 & 77 & 8 & & & 30 & 108 & 16 & 133 & 1 \\
\hline & & 37 & 97 & 14 & 89 & 7 & & & 100 & 100 & 5 & 99 & 1 \\
\hline & $7(R, S)-\mathrm{ST}-\Delta^{8}$-11-dihomo-IsoF & 3 & 93 & 13 & 92 & 32 & & ent-16(R,S)-13-epi-ST- $\Delta^{14}$ & 1 & 89 & 9 & 94 & 4 \\
\hline & & 10 & 97 & 10 & 104 & 11 & & $\begin{array}{l}\text { 9- } \\
\text { PhytoF } 1 *)\end{array}$ & 5 & 89 & 6 & 88 & 3 \\
\hline & & 30 & 99 & 9 & 101 & 2 & & & 14 & 91 & 2 & 92 & 1 \\
\hline & & 100 & 100 & 12 & 96 & 7 & & & 47 & 93 & 6 & 86 & 1 \\
\hline & $17(R, S)$-10-epi-SC- $\Delta^{15}$-11-dihomo-IsoF & 2 & 109 & 7 & 90 & 15 & & ent-16(R,S)-13-epi-ST- $\Delta^{14}$ & 2 & 104 & 6 & 100 & 4 \\
\hline & $1 *)$ & 5 & 93 & 7 & 103 & 2 & & $\begin{array}{l}\text { 9- } \\
\text { PhytoF } 2 *)\end{array}$ & 5 & 91 & 2 & 92 & 4 \\
\hline & & 16 & 107 & 9 & 122 & 8 & & & 16 & 94 & 4 & 97 & 2 \\
\hline & & 52 & 105 & 8 & 97 & 9 & & & 53 & 97 & 7 & 93 & 5 \\
\hline & $17(R, S)-10$-epi-SC- $\Delta^{15}$-11-dihomo-IsoF & 1 & 96 & 6 & 96 & 13 & DHA & $4(R, S)-4-\mathrm{F}_{4 \mathrm{t}}-\mathrm{NeuroP}$ & 3 & 92 & 16 & 114 & 5 \\
\hline & $2 *)$ & 5 & 96 & 6 & 108 & 1 & & & 10 & 83 & 7 & 98 & 3 \\
\hline & & 14 & 103 & 11 & 124 & 10 & & & 30 & 85 & 16 & 74 & 9 \\
\hline & & 48 & 101 & 9 & 97 & 10 & & & 100 & 95 & 15 & 84 & 3 \\
\hline \multirow[t]{12}{*}{ EPA } & $5(R, S)-5-\mathrm{F}_{3 \mathrm{t}}$-IsoP & 3 & 110 & 11 & 150 & 2 & & $10-\mathrm{F}_{4 \mathrm{t}}-$ NeuroP & 3 & 113 & 4 & 124 & 3 \\
\hline & & 10 & 104 & 3 & 102 & 7 & & & 10 & 109 & 2 & 112 & 3 \\
\hline & & 30 & 96 & 6 & 92 & 2 & & & 30 & 119 & 8 & 108 & 2 \\
\hline & & 100 & 103 & 5 & 89 & 0 & & & 100 & 113 & 12 & 103 & 1 \\
\hline & $8-\mathrm{F}_{3 \mathrm{t}}$-IsoP & 3 & 103 & 5 & 97 & 3 & & $10-e p i-10-\mathrm{F}_{4 \mathrm{t}}-\mathrm{NeuroP}$ & 3 & 105 & 9 & 118 & 12 \\
\hline & & 10 & 97 & 3 & 94 & 4 & & & 10 & 99 & 5 & 100 & 2 \\
\hline & & 30 & 96 & 4 & 94 & 3 & & & 30 & 106 & 10 & 87 & 3 \\
\hline & & 100 & 99 & 8 & 93 & 3 & & & 100 & 102 & 10 & 97 & 4 \\
\hline & 8-epi-8-F $3 \mathrm{t}^{-}$IsoP & 3 & 98 & 5 & 107 & 1 & & $14(R, S)-14-\mathrm{F}_{4 \mathrm{t}}-$ NeuroP & 3 & \multicolumn{2}{|c|}{$<$ LLOQ } & \multicolumn{2}{|c|}{$<$ LLOQ } \\
\hline & & 10 & 91 & 3 & 96 & 3 & & & 10 & \multicolumn{2}{|l|}{$<$ LLOQ } & \multicolumn{2}{|c|}{$<$ LLOQ } \\
\hline & & 30 & 88 & 4 & 86 & 2 & & & 30 & 103 & 5 & 100 & 12 \\
\hline & & 100 & 95 & 5 & 91 & 4 & & & 100 & 101 & 7 & 97 & 17 \\
\hline n6- & $4(R, S)-4-\mathrm{F}_{3 \mathrm{t}}-\mathrm{NeuroP}_{\mathrm{n} 6}$ & 3 & 93 & 11 & 105 & 22 & & $4(R, S)-\mathrm{ST}-\Delta^{5}-8$-NeuroF & 3 & $<$ LLOQ & & $<$ LLOQ & \\
\hline DPA & & 10 & 77 & 13 & 94 & 1 & & & 10 & $<$ LLOQ & & $<$ LLOQ & \\
\hline & & 30 & 78 & 22 & 63 & 9 & & & 30 & $<$ LLOQ & & $<$ LLOQ & \\
\hline & & 100 & 84 & 17 & 79 & 11 & & & 100 & 93 & 22 & 78 & 6 \\
\hline
\end{tabular}

increased. Nevertheless, our approach is still one of the three most sensitive methods described so far for the detection of IsoP. Moreover, it is the most comprehensive approach for the simultaneous quantification of prostanoid-like autoxidation products and covers more analytes than all previous methods.

Matching between method sensitivity and expected concentration in biological samples one should take into account that the baseline levels of IsoP and IsoF are very low, e.g. the commonly analyzed $15(R, S)-15-\mathrm{F}_{2 \mathrm{t}}$-IsoP is in the range of $40-170 \mathrm{pg} / \mathrm{mL}$ human plasma (total, i.e. free and esterified) of healthy subjects [53], corresponding to $0.1-0.5 \mathrm{nM}$. Sufficient sample preparation including a pre-concentration step as carried out in the presented method by an optimized SPE procedure is therefore needed to determine these compounds in biological samples.

For quantification, calibration curves at 10 concentration levels covering a concentration range from 0.1 to $500 \mathrm{nM}$ for each analyte were prepared. With linear least square regression based on $1 / \mathrm{x}^{2}$ weighting correlation coefficients $\geq 0.994$ were achieved for all analytes indicating linearity for the covered concentration range (Table 1). The highest calibration level was set as upper limit of quantification (ULOQ), however does not represent the end of the linear detector response. Taking the low physiological 
A

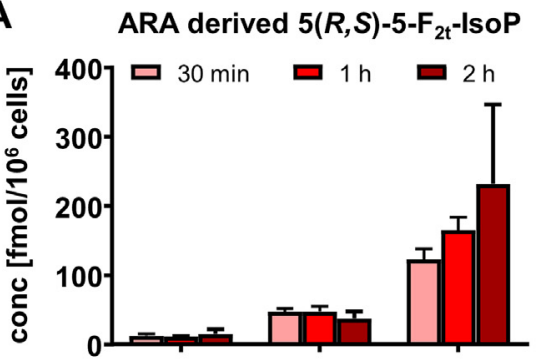

B

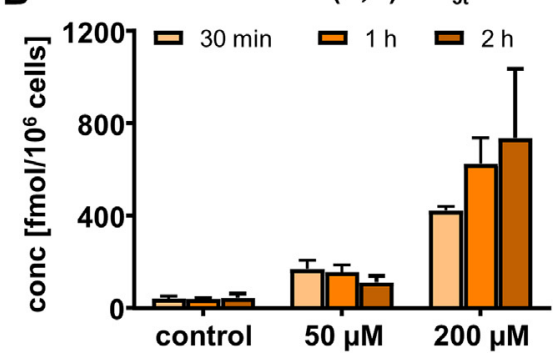

D

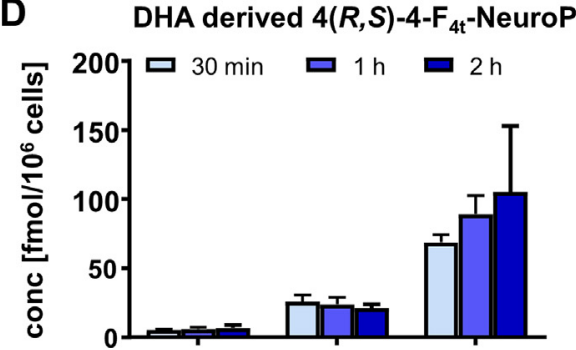

A

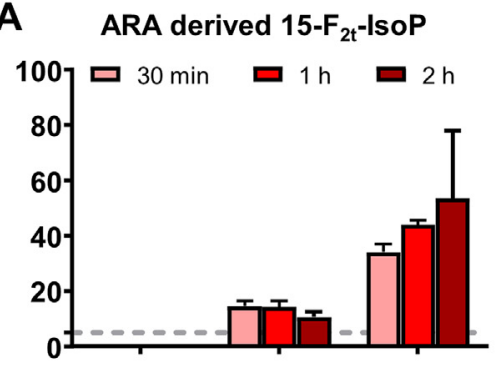

C AdA derived

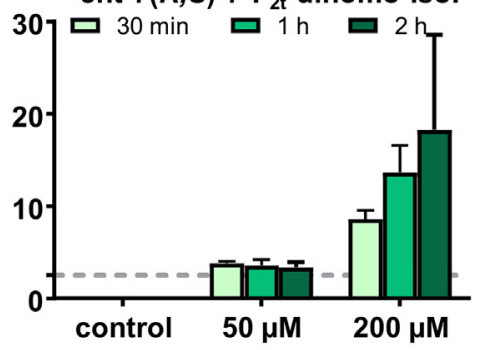

D

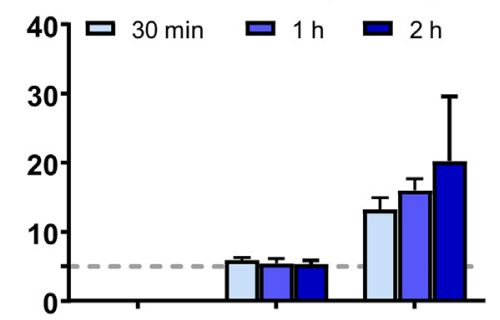

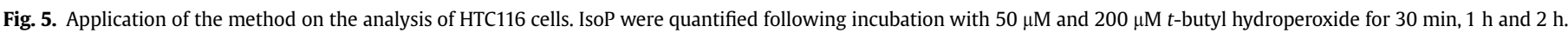

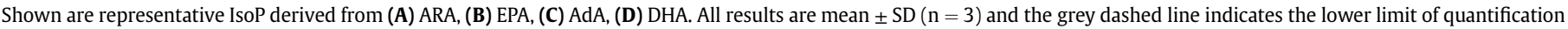
(LLOQ).

concentration of IsoP and IsoF into account the calibration of higher concentration as carried out in other methods [30-33] was for the intended application not necessary.

\subsection{Extraction efficiency}

The extraction efficiency from biological samples was characterized based on the recovery of IS spiked to the sample prior extraction. For the evaluation of the extraction efficiency of the used sample preparation procedure different volumes (200 $\mu \mathrm{L}$, $500 \mu \mathrm{L}, 1000 \mu \mathrm{L}$ ) of plasma from healthy volunteers were extracted by SPE. As shown in Fig. 4, recoveries in the range of $80-100 \%$ for all IS independent from the used plasma volume indicate a sufficient extraction for quantitative determination.

Regarding all IsoP and IsoF covered by the method, no IsoF and only ARA derived $\mathrm{F}_{2 \mathrm{t}}$-IsoP were detected in the analyzed human plasma from healthy subjects. The most abundant regioisomer was $5(R, S)-5-\mathrm{F}_{2 \mathrm{t}}$-IsoP with comparable concentration for all investigated volumes ( $128 \pm 13 ; 138 \pm 6$ and $132 \pm 6 \mathrm{pM}$ for $200 \mu \mathrm{L}, 500 \mu \mathrm{L}$ and $1000 \mu \mathrm{L}$ respectively) indicating a good accuracy and precision regardless of the amount of sample/matrix injected. For $15-\mathrm{F}_{2 \mathrm{t}}-\mathrm{IsoP}$, which is the most studied regioisomer, lower levels were detected (48 \pm 1 and $38 \pm 1 \mathrm{pM}$ for $500 \mu \mathrm{L}$ and $1000 \mu \mathrm{L}$ respectively). This is consistent with previous findings reporting concentrations for $15(R, S)-15-\mathrm{F}_{2 \mathrm{t}}$-IsoP in the range of $16-48 \mathrm{pg} / \mathrm{mL}(45-135 \mathrm{pM})$ [19] and $3-25 \mathrm{pg} / \mathrm{mL}(8-71 \mathrm{pM})$ [54] in human plasma of healthy subjects.

\subsection{Intra- and interday accuracy and precision}

Intra- and interday accuracy and precision were characterized oriented on the guideline on bioanalytical method validation of the European Medicines Agency. In order to evaluate the accuracy and precision of the analytical procedure, human plasma samples spiked at four concentration levels prior extraction were analyzed in four replicates. The intraday accuracy ranged for all analytes from 77 to $121 \%$ indicating low interference of plasma matrix and good extraction efficiency of the analytes using the presented SPE procedure. Intraday precision calculated as RSD was $<15 \%$ for almost all analytes at all spiking levels with few exceptions being, however, below $22 \%$ (Table 2 ). Interday precision was better, below $11 \%$ for 10,30 and $100 \mathrm{nM}$ spiking levels, thus indicating a stable method which allows the analysis of large sample batches. However, at the low concentration level ( $3 \mathrm{nM}$ ), which is close to LLOQ, RSDs showed a trend towards higher values, but were still $<22 \%$ for almost all analytes, except $7(R, S)-\mathrm{ST}-\Delta^{8}-11$-dihomo-IsoF (LLOQ of $2 \mathrm{nM}, \mathrm{RSD}=32 \%$, Table 2 ).

\subsection{Formation of IsoP in cell culture}

The developed method was applied to investigate the formation of IsoP and IsoF in HCT116 cells during oxidative stress caused by $t$ $\mathrm{BOOH}$. First, the viability of HCT116 cells treated with increasing doses of $t-\mathrm{BOOH}$ for $2 \mathrm{~h}$ was determined with the MTS assay, revealing no effects at a dose of $50 \mu \mathrm{M}$ and a moderate reduction of 
the viability to $84 \%$ in cells incubated with $200 \mu \mathrm{M} t$-BOOH (SI, Fig $S 5)$. Following incubation a large number of IsoP were detected in the cells, i.e. $5(R, S)-5-\mathrm{F}_{2 \mathrm{t}}-\mathrm{IsoP}, 15-\mathrm{F}_{2 \mathrm{t}}$-IsoP, ent-7(R,S)-7- $\mathrm{F}_{2 \mathrm{t}}$-dihomo-

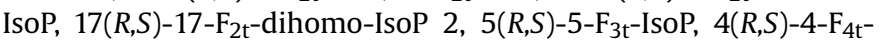
NeuroP, 10-F4t-NeuroP, 10-epi-10-F4t-IsoP (Fig. 5, Table S3). In control incubations the levels of the detected IsoP were low or below the LLOQ (Table S3, Fig. 5), with EPA derived 5(R,S)-5- $\mathrm{F}_{3 \mathrm{t}}$-IsoP being most abundant.

Regarding distribution of the different IsoP, a dominant formation of regioisomers carrying the side chain hydroxyl group in proximity to the carboxy terminus was observed for the IsoP formed from all different PUFA: $5(R, S)-5-\mathrm{F}_{2 \mathrm{t}}-\mathrm{IsoP}, 5(R, S)-5-\mathrm{F}_{3 \mathrm{t}}-\mathrm{IsoP}$, ent-7(R,S)-7- $\mathrm{F}_{2 \mathrm{t}}$-dihomo-IsoP and $4(R, S)-4-\mathrm{F}_{4 \mathrm{t}}-$ NeuroP. At high concentrations of $t$ - $\mathrm{BOOH}$ also other regiosomers were formed and the IsoP concentration increased dose dependently with the $t$ $\mathrm{BOOH}$ concentration. IsoP levels after $30 \mathrm{~min}$ with $200 \mu \mathrm{M}$ were generally higher than after $2 \mathrm{~h}$ of incubation with $50 \mu \mathrm{M} t-\mathrm{BOOH}$. Moreover, with $200 \mu \mathrm{M} t-\mathrm{BOOH}$, even if not statistically significant, a trend towards higher levels of IsoP with increasing incubation time was observed while in incubations with $50 \mu \mathrm{M} t$-BOOH similar concentrations of IsoP were found for the different time points. This may indicate a cellular defense mechanism against ROS and thus IsoP formation decreased. It is also remarkable that with higher $t$ $\mathrm{BOOH}$ concentration the regioisomers with the side chain hydroxyl group in proximity to the carboxy terminus were stronger elevated than other regiosomers (Fig. 5), which may indicate not only differences in formation but also in the metabolism rates of the different regioisomers. This becomes particularly evident for the ARA derived IsoP. Here, 3-4 fold higher levels of $5(R, S)-5-\mathrm{F}_{2 \mathrm{t}}$-IsoP were found compared to $15-\mathrm{F}_{2 \mathrm{t}}$-IsoP while in livers of $\mathrm{CCl}_{4}$ exposed rats a ratio of 1.5:1 was found [12]. However, it should be noted that these differences might also indicate species specific formation and metabolism rates of different regioisomers. The metabolism of the $\mathrm{F}_{2}$-IsoPs, particularly $15-\mathrm{F}_{2 \mathrm{t}}$-IsoP has been well described $[55,56]$. By contrast the metabolism of the NeuroPs is not yet well understood, except an earlier investigation reported by Lawson et al. who showed that 7- $\mathrm{F}_{4 \mathrm{t}}-\mathrm{NeuroP}$ is readily beta-oxidized to $5-\mathrm{F}_{3 \mathrm{t}}$-IsoP (an isoprostanoid metabolite from EPA oxidation) and excreted [57] whereas certain NeuroPs like $4-\mathrm{F}_{4 \mathrm{t}}-\mathrm{NeuroP}$ are probably more stable due to the presence of the side chain hydroxyl group at C4, which can limit access of the enzymes involved in beta-oxidation as it is the case for 5-hydroxyeicosanoids [58].

These results indicate that either the cellular formation is cell specific or the products are metabolized at different rates. The cellular formation of IsoP in response to oxidative stress and especially the resulting IsoP pattern warrants further investigation. In particular, application of different cell types and cell lines, e.g. deficient in different ROS defense mechanisms, should be used to understand the intracellular formation and the metabolic fate of IsoP. This investigation will allow gaining more insights into the role of IsoP in biology and help to identify specific biomarkers for distinct physiological states. With the developed method described herein, we provide the ideal tool to comprehensively quantify IsoP derived from all biologically relevant PUFA.

\section{Acknowledgement}

Our work is supported by a grant (01EA1702) of the Federal Ministry of Education and Research of Germany (BMBF) in the framework of the Joint Program Initiative ERA-HDHL to NHS, in part by the German Research Foundation (DFG, Grant SCHE 1801 to NHS) and by the Fonds der Chemischen Industrie in form of a PhD scholarship to KR. TD thanks his two colleagues, Dr Valérie BultelPoncé and Dr Alexandre Guy, for having synthesized the two unlabeled odd-chain IS.

\section{Appendix A. Supplementary data}

Supplementary data related to this article can be found at https://doi.org/10.1016/j.aca.2017.11.002.

\section{References}

[1] A. Weidinger, A. Kozlov, Biological activities of reactive oxygen and nitrogen species: oxidative stress versus signal transduction, Biomolecules 5 (2015) 472.

[2] H. Sies, 1-Oxidative Stress: Introductory Remarks, Oxidative Stress, Academic Press, London, 1985, pp. 1-8.

[3] D.P. Jones, H. Sies, The redox code, Antioxidants Redox Signal. 23 (2015) $734-746$.

[4] H. Sies, Biochemistry of oxidative stress, Angewandte Chemie Int. Ed. Engl. 25 (1986) 1058-1071.

[5] G. Stark, Functional consequences of oxidative membrane damage, J. Membr. Biol. 205 (2005) 1-16.

[6] H. Yin, L. Xu, N.A. Porter, Free radical lipid peroxidation: mechanisms and analysis, Chem. Rev. 111 (2011) 5944-5972.

[7] D. Giustarini, I. Dalle-Donne, D. Tsikas, R. Rossi, Oxidative stress and human diseases: origin, link, measurement, mechanisms, and biomarkers, Crit. Rev. Clin. Lab. Sci. 46 (2009) 241-281.

[8] M.B. Kadiiska, B.C. Gladen, D.D. Baird, D. Germolec, L.B. Graham, C.E. Parker A. Nyska, J.T. Wachsman, B.N. Ames, S. Basu, N. Brot, G.A. Fitzgerald, R.A. Floyd, M. George, J.W. Heinecke, G.E. Hatch, K. Hensley, J.A. Lawson, L.J. Marnett, J.D. Morrow, D.M. Murray, J. Plastaras, L.J. Roberts 2nd, J. Rokach, M.K. Shigenaga, R.S. Sohal, J. Sun, R.R. Tice, D.H. Van Thiel, D. Wellner, P.B. Walter, K.B. Tomer, R.P. Mason, J.C. Barrett, Biomarkers of oxidative stress study II: are oxidation products of lipids, proteins, and DNA markers of CCl4 poisoning? Free Radic. Biol. Med. 38 (2005) 698-710.

[9] J.D. Morrow, J.A. Awad, H.J. Boss, I.A. Blair, L.J. Roberts 2nd, Non-cyclooxygenase-derived prostanoids (F2-isoprostanes) are formed in situ on phospholipids, Proc. Natl. Acad. Sci. U. S. A. 89 (1992) 10721-10725.

[10] J.D. Morrow, L.J. Roberts, V.C. Daniel, J.A. Awad, O. Mirochnitchenko, L.L. Swift, R.F. Burk, Comparison of formation of D2/E2-isoprostanes and F2-isoprostanes in vitro and in vivo-effects of oxygen tension and glutathione, Archives Biochem. Biophysics 353 (1998) 160-171.

[11] R.J. Waugh, R.C. Murphy, Mass spectrometric analysis of four regioisomers of F2-isoprostanes formed by free radical oxidation of arachidonic acid, J. Am. Soc. Mass Spectrom. 7 (1996) 490-499.

[12] R.J. Waugh, J.D. Morrow, L.J. Roberts Ii, R.C. Murphy, Identification and relative quantitation of F2-Isoprostane regioisomers formed in vivo in the rat, Free Radic. Biol. Med. 23 (1997) 943-954.

[13] J.P. Fessel, N.A. Porter, K.P. Moore, J.R. Sheller, L.J. Roberts 2nd, Discovery of lipid peroxidation products formed in vivo with a substituted tetrahydrofuran ring (isofurans) that are favored by increased oxygen tension, Proc. Natl. Acad. Sci. U. S. A. 99 (2002) 16713-16718.

[14] C. Cuyamendous, K.S. Leung, T. Durand, J.C.-Y. Lee, C. Oger, J.-M. Galano, Synthesis and discovery of phytofurans: metabolites of $\alpha$-linolenic acid peroxidation, Chem. Commun. 51 (2015) 15696-15699.

[15] K.S. Leung, V. Bultel-Poncé, A. Guy, T. Durand, J.M. Galano, C.Y. Lee, C. Oger, Total syntheses and in vivo quantitation of novel Phytofurans derived from alpha-linolenic acid, Eur. J. Org. Chem. (2017) 2486-2490.

[16] E.R. Skinner, C. Watt, J.A. Besson, P.V. Best, Differences in the fatty acid composition of the grey and white matter of different regions of the brains of patients with Alzheimer's disease and control subjects, Brain a J. Neurol. 116 (Pt 3) (1993) 717-725.

[17] M. VanRollins, R.L. Woltjer, H. Yin, J.D. Morrow, T.J. Montine, F2-dihomoisoprostanes arise from free radical attack on adrenic acid, J. Lipid Res. 49 (2008) 995-1005.

[18] H. Schweer, B. Watzer, H.W. Seyberth, R.M. Nusing, Improved quantification of 8-epi-prostaglandin F2 alpha and F2-isoprostanes by gas chromatography/ triple-stage quadrupole mass spectrometry: partial cyclooxygenasedependent formation of 8-epi-prostaglandin F2 alpha in humans, J. Mass Spectrom. JMS 32 (1997) 1362-1370.

[19] C. Signorini, M. Comporti, G. Giorgi, Ion trap tandem mass spectrometric determination of F2-isoprostanes, J. Mass Spectrom. JMS 38 (2003) 1067-1074.

[20] E.S. Musiek, J.K. Cha, H. Yin, W.E. Zackert, E.S. Terry, N.A. Porter, T.J. Montine, J.D. Morrow, Quantification of F-ring isoprostane-like compounds (F4neuroprostanes) derived from docosahexaenoic acid in vivo in humans by a stable isotope dilution mass spectrometric assay, J. Chromatogr. B, Anal. Technol. Biomed. Life Sci. 799 (2004) 95-102.

[21] C.Y. Lee, A.M. Jenner, B. Halliwell, Rapid preparation of human urine and plasma samples for analysis of F2-isoprostanes by gas chromatography-mass spectrometry, Biochem. Biophysical Res. Commun. 320 (2004) 696-702.

[22] C.Y. Lee, S.H. Huang, A.M. Jenner, B. Halliwell, Measurement of F2isoprostanes, hydroxyeicosatetraenoic products, and oxysterols from a single plasma sample, Free Radic. Biol. Med. 44 (2008) 1314-1322.

[23] C. Signorini, L. Ciccoli, S. Leoncini, S. Carloni, S. Perrone, M. Comporti, W. Balduini, G. Buonocore, Free iron, total F-isoprostanes and total F-neuroprostanes in a model of neonatal hypoxic-ischemic encephalopathy: 
neuroprotective effect of melatonin, J. Pineal Res. 46 (2009) 148-154.

[24] G.L. Milne, B. Gao, E.S. Terry, W.E. Zackert, S.C. Sanchez, Measurement of F2isoprostanes and isofurans using gas chromatography-mass spectrometry, Free Radic. Biol. Med. 59 (2013) 36-44.

[25] D.R. Briskey, G.R. Wilson, R.G. Fassett, J.S. Coombes, Optimized method for quantification of total F2-isoprostanes using gas chromatography-tandem mass spectrometry, J. Pharm. Biomed. Anal. 90 (2014) 161-166.

[26] W. Yan, G.D. Byrd, M.W. Ogden, Quantitation of isoprostane isomers in human urine from smokers and nonsmokers by LC-MS/MS, J. Lipid Res. 48 (2007) 1607-1617.

[27] S. Medina, R. Dominguez-Perles, J.I. Gil, F. Ferreres, C. Garcia-Viguera, J.M. Martinez-Sanz, A. Gil-Izquierdo, A ultra-pressure liquid chromatography/ triple quadrupole tandem mass spectrometry method for the analysis of 13 eicosanoids in human urine and quantitative 24 hour values in healthy volunteers in a controlled constant diet, Rapid Commun. Mass Spectrom. RCM 26 (2012) 1249-1257.

[28] J.K. Prasain, A. Arabshahi, P.R. Taub, S. Sweeney, R. Moore, J.D. Sharer, S. Barnes, Simultaneous quantification of F2-isoprostanes and prostaglandins in human urine by liquid chromatography tandem-mass spectrometry, J. Chromatogr. B 913-914 (2013) 161-168.

[29] J. Larose, P. Julien, J.F. Bilodeau, Analysis of F2-isoprostanes in plasma of pregnant women by HPLC-MS/MS using a column packed with core-shell particles, J. Lipid Res. 54 (2013) 1505-1511.

[30] S. Medina, I.D. Miguel-Elizaga, C. Oger, J.M. Galano, T. Durand, M. MartinezVillanueva, M.L. Castillo, I. Villegas-Martinez, F. Ferreres, P. Martinez-Hernandez, A. Gil-Izquierdo, Dihomo-isoprostanes-nonenzymatic metabolites of AdA-are higher in epileptic patients compared to healthy individuals by a new ultrahigh pressure liquid chromatography-triple quadrupole-tandem mass spectrometry method, Free Radic. Biol. Med. 79 (2015) 154-163.

[31] J. Collado-Gonzalez, S. Medina, T. Durand, A. Guy, J.M. Galano, A. Torrecillas, F. Ferreres, A. Gil-Izquierdo, New UHPLC-QqQ-MS/MS method for quantitative and qualitative determination of free phytoprostanes in foodstuffs of commercial olive and sunflower oils, Food Chem. 178 (2015) 212-220.

[32] C. Chafer-Pericas, L. Rahkonen, A. Sanchez-Illana, J. Kuligowski, I. TorresCuevas, M. Cernada, E. Cubells, A. Nunez-Ramiro, S. Andersson, M. Vento, J. Escobar, Ultra high performance liquid chromatography coupled to tandem mass spectrometry determination of lipid peroxidation biomarkers in newborn serum samples, Anal. Chim. Acta 886 (2015) 214-220.

[33] A. Dupuy, P. Le Faouder, C. Vigor, C. Oger, J.M. Galano, C. Dray, J.C. Lee, P. Valet, C. Gladine, T. Durand, J. Bertrand-Michel, Simultaneous quantitative profiling of 20 isoprostanoids from omega- 3 and omega- 6 polyunsaturated fatty acids by LC-MS/MS in various biological samples, Anal. Chim. Acta 921 (2016) $46-58$.

[34] M.E. Yonny, A. Rodríguez Torresi, C. Cuyamendous, G. Réversat, C. Oger, JM. Galano, T. Durand, C. Vigor, M.A. Nazareno, Thermal stress in melon plants: phytoprostanes and phytofurans as oxidative stress biomarkers and the effect of antioxidant supplementation, J. Agric. Food Chem. 64 (2016) 8296-8304.

[35] Z. Wang, G. Ciabattoni, C. Creminon, J. Lawson, G.A. Fitzgerald, C. Patrono, J. Maclouf, Immunological characterization of urinary 8-epi-prostaglandin F2 alpha excretion in man, J. Pharmacol. Exp. Ther. 275 (1995) 94-100.

[36] S. Basu, Radioimmunoassay of 8-iso-prostaglandin F2alpha: an index for oxidative injury via free radical catalysed lipid peroxidation, Prostagl. Leukot. Essent. Fat. Acids 58 (1998) 319-325.

[37] D. Il'yasova, J.D. Morrow, A. Ivanova, L.E. Wagenknecht, Epidemiological marker for oxidant status: comparison of the ELISA and the gas chromatography/mass spectrometry assay for urine 2,3-dinor-5,6-dihydro-15-F2t-isoprostane, Ann. Epidemiol. 14 (2004) 793-797.

[38] J. Klawitter, M. Haschke, T. Shokati, J. Klawitter, U. Christians, Quantification of 15-F2t-isoprostane in human plasma and urine: results from enzyme-linked immunoassay and liquid chromatography/tandem mass spectrometry cannot be compared, Rapid Commun. Mass Spectrom. RCM 25 (2011) 463-468.

[39] D. Il'yasova, J.D. Morrow, A. Ivanova, L.E. Wagenknecht, Epidemiological marker for oxidant status: comparison of the ELISA and the gas chromatography/mass spectrometry assay for urine 2,3-dinor-5,6-dihydro-15-F2t-isoprostane, Ann. Epidemiol. 14 (2004) 793-797.

[40] C.F. Labuschagne, E.C. Stigter, M.M. Hendriks, R. Berger, J. Rokach,
H.C. Korswagen, A.B. Brenkman, Quantification of in vivo oxidative damage in Caenorhabditis elegans during aging by endogenous F3-isoprostane measurement, Aging Cell 12 (2013) 214-223.

[41] J. Aszyk, J. Kot, Y. Tkachenko, M. Woźniak, A. Bogucka-Kocka, A. Kot-Wasik Novel liquid chromatography method based on linear weighted regression for the fast determination of isoprostane isomers in plasma samples using sensitive tandem mass spectrometry detection, J. Chromatogr. B 1051 (2017) 17-23.

[42] M.L. Chung, K.Y. Lee, C.Y. Lee, Profiling of oxidized lipid products of marine fish under acute oxidative stress, Food Chem. Toxicol. Int. J. Publ. Br. Ind. Biol. Res. Assoc. 53 (2013) 205-213.

[43] C. Oger, Y. Brinkmann, S. Bouazzaoui, T. Durand, J.M. Galano, Stereocontrolled access to isoprostanes via a Bicyclo[3.3.0]octene framework, Org. Lett. 10 (2008) 5087-5090.

[44] M. Mimmler, S. Peter, A. Kraus, S. Stroh, T. Nikolova, N. Seiwert S. Hasselwander, C. Neitzel, J. Haub, B.H. Monien, P. Nicken, P. Steinberg J.W. Shay, B. Kaina, J. Fahrer, DNA damage response curtails detrimenta replication stress and chromosomal instability induced by the dietary carcinogen PhIP, Nucleic Acids Res. 44 (2016) 10259-10276.

[45] A.I. Ostermann, I. Willenberg, N.H. Schebb, Comparison of sample preparation methods for the quantitative analysis of eicosanoids and other oxylipins in plasma by means of LC-MS/MS, Anal. Bioanal. Chem. 407 (2015) 1403-1414.

46] S.H. Hwang, H.-J. Tsai, J-Y. Liu, C. Morisseau, B.D. Hammock, Orally bioavailable potent soluble epoxide hydrolase inhibitors, J. Med. Chem. 50 (2007) 3825-3840.

[47] EMEA/CHMP/EWP/192217/2009 Rev. 1Corr. 2, Guideline on Bioanalytical Method Validation, European Medicines Agency, 2011.

[48] I. Willenberg, A.K. Meschede, F. Gueler, M.S. Jang, N. Shushakova, N.H. Schebb Food polyphenols fail to cause a biologically relevant reduction of COX-2 activity, PLoS One 10 (2015) e0139147.

[49] I. Willenberg, K. Rund, S. Rong, N. Shushakova, F. Gueler, N.H. Schebb, Characterization of changes in plasma and tissue oxylipin levels in LPS and CLP induced murine sepsis, Inflamm. Res. Offic. J. Eur. Histamine Res. Soc. 65 (2016) 133-142 [et al.].

[50] R.C. Murphy, R.M. Barkley, K. Zemski Berry, J. Hankin, K. Harrison, C. Johnson, J. Krank, A. McAnoy, C. Uhlson, S. Zarini, Electrospray ionization and tandem mass spectrometry of eicosanoids, Anal. Biochem. 346 (2005) 1-42.

[51] A. de La Torre, Y.Y. Lee, C. Oger, P.T. Sangild, T. Durand, J.C.-Y. Lee, J.-M. Galano, Synthesis, discovery, and quantitation of dihomo-isofurans: biomarkers for in vivo adrenic acid peroxidation, Angew. Chem. Int. Ed. 53 (2014) 6249-6252.

[52] A. de la Torre, Y.Y. Lee, A. Mazzoni, A. Guy, V. Bultel-Poncé, T. Durand, C. Oger J.C.-Y. Lee, J.-M. Galano, Total syntheses and in vivo quantitation of nove neurofuran and dihomo-isofuran derived from docosahexaenoic acid and adrenic acid, Chem. - A Eur. J. 21 (2015) 2442-2446.

[53] N.E. Bastani, T.E. Gundersen, R. Blomhoff, Determination of 8-epi PGF(2alpha) concentrations as a biomarker of oxidative stress using triple-stage liquid chromatography/tandem mass spectrometry, Rapid Commun. Mass Spectrom. RCM 23 (2009) 2885-2890.

[54] M. Haschke, Y.L. Zhang, C. Kahle, J. Klawitter, M. Korecka, L.M. Shaw U. Christians, HPLC-atmospheric pressure chemical ionization MS/MS for quantification of 15-F2t-isoprostane in human urine and plasma, Clin. Chem. 53 (2007) 489-497.

55] C. Chiabrando, A. Valagussa, C. Rivalta, T. Durand, A. Guy, E. Zuccato, P. Villa, J.C. Rossi, R. Fanelli, Identification and measurement of endogenous betaoxidation metabolites of 8-epi-Prostaglandin F2alpha, J. Biol. Chem. 274 (1999) 1313-1319.

[56] L.J. Roberts, K.P. Moore, W.E. Zackert, J.A. Oates, J.D. Morrow, Identification of the major urinary metabolite of the F-2-isoprostane 8-iso-prostaglandin F-2 alpha in humans, J. Biol. Chem. 271 (1996) 20617-20620.

[57] J.A. Lawson, S. Kim, W.S. Powell, G.A. FitzGerald, J. Rokach, Oxidized derivatives of omega-3 fatty acids: identification of IPF3 alpha-VI in human urine, J. Lipid Res. 47 (2006) 2515-2524.

[58] D.O. Stene, R.C. Murphy, Metabolism of leukotriene E4 in isolated rat hepatocytes. Identification of beta-oxidation products of sulfidopeptide leukotrienes, J. Biol. Chem. 263 (1988) 2773-2778. 